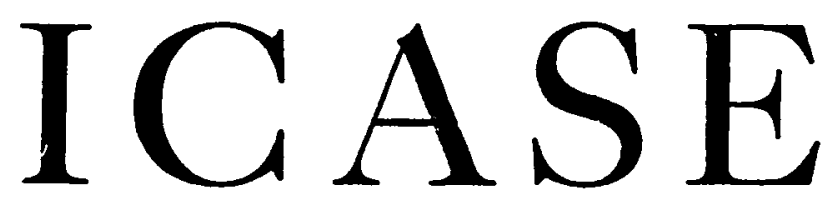

NUMERICAL METHODS FOR STIFF SYSTEMS OF

TWO-POINT BOUNDARY VALUE PROBLEMS

Joseph E. F1aherty

and

Robert E. O'Malley, Jr.

Contract Nos. NAS1-15810 and NAS1-17070 April 1983

INSTITUTE FOR COMPUTER APPLICATIONS IN SCIENCE AND ENGINEERING NASA Langley Research Center, Hampton, Virginia 23665

Operated by the Universitite Space Research Association

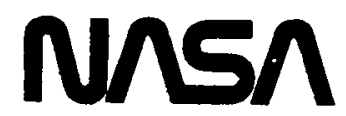

National Aeronautics and Space Admınıstration

Langley Research Center Hampton, Virgını 23665

\section{LBBARY GOPY}

$$
\text { l. } 2 y_{1}>61983
$$

IANGLEY RESEAFCH CENTER LIBRARY, NASA HA::PTON, VIREINUA 


\title{
NUMERICAL METHODS FOR STIFF SYSTEMS OF \\ TWO-POINT BOUNDARY VALUE PROBLEMS*
}

\author{
Joseph E. Flaherty \\ and \\ Robert E. O'Malley, Jr. \\ Department of Mathematıcal Sciences \\ Rensselaer Polytechnic Institute \\ Troy, New York 12181
}

ABSTRACT

We develop numerical procedures for constructing asymptotic solutions of certain nonlinear singularly perturbed vector two-point boundary value problems having boundary layers at one or both endpoints. The asymptotic approximations are generated numerıcally and can either be used as is or to furnish a general purpose two-point boundary value code with an initial approximation and the nonuniform computational mesh needed for such problems. The procedures are applied to a model problem that has multıple solutions and to problems describing the deformation of a thin nonlinear elastic beam that is resting on an elastic foundation.

* This research was partlally supported by the U. S. Air Force office of Scientific Research, Air Force Systems Command, USAF, under Grant Number AFOSR 80-0192, the Office of Naval Research under Contract Number N00014-81K-056, and by the U. S. Army Research Office under Grant Number DAAG29-82-K-0197. Partial support was also provided under NASA Contract Nos. NAS1-15810 and NAS1-17070 while the authors were in residence at the Institute for Computer Applicatıons in Science and Engıneering, Hampton, VA 23665. The United States Government is authorized to reproduce and distribute reprints for government purposes notwithstanding any copyright notation thereon. 


\section{Introduction}

Inztzal value problems for stiff systems of ordınary differentzal equations are now considered to be relatively tractzble numerically (cf. Enrıght et al. [7]). However, codes for stıff (or sıngularly perturbed) boundary value problems are not readily available, even though these problems arıse in a great many applications.

In this paper we consider asymptotıc and numerical methods for singularly perturbed two-point boundary value problems of the form

$$
\begin{aligned}
& \underset{\sim}{\dot{x}}=\underset{\sim}{f}(\underset{\sim}{x}, \underset{\sim}{y}, t, \varepsilon) \quad, \quad \underset{\sim}{\dot{y}}=\underset{\sim}{g}(\underset{\sim}{x}, \underset{\sim}{y}, t, \varepsilon) \\
& \underset{\sim}{a}(0), \underset{\sim}{y}(0), \varepsilon)=0 \sim
\end{aligned}
$$

where $\underset{\sim}{x} \underset{\sim}{y}, \underset{\sim}{a}$, and $\underset{\sim}{b}$ are vectors of dimension $m, n, q$, and $r=m+n-q$, respectively, and $\varepsilon$ is a small positive parameter.

Although many special problems of this form can be solved by known asymptotıc or numerical technıques, the general problem is very difficult and beyond our current understanding. The form of equations $(1,1,2)$ imply that, whenever $\underset{\sim}{g}$ is not small, $\underset{\sim}{\mathrm{y}}$ varies rapldly relative to $\underset{\sim}{\mathrm{x}}$. The behavior of the solution in these zones of rapid transition can be very complicated. For example, $y$ can "Jump" abruptly in a narrow boundary layer near $t=0$ and/or 1 . These jumps can also occur at interior locations where solutions or their derivatives will become unbounded as $\varepsilon+0$. The locations of the interlor layers are generally unknown and must be determined as part of the solution process. Examples of these and other phenomena are discussed in, e.g., O'Malley [20], Kevorkian and Cole [18], Pearson [24, 25], Hemker [15], and Flaherty and O'Malley [11]. 
The traditional numerical technıques for two-polnt boundary value problems all have difficulties with singularly perturbed problems unless the grid that is used for the discretization is appropriately fine, at least withın boundary or interıor layers. If the grid is not fine enough to resolve the layers, the computed solution typically exhibits spurious mesh oscillations. There are, however, special purpose schemes that can solve some singularly perturbed boundary value problems without using a fine discretization in transition regions. Most notable among these are the "upwind" or one-sided finite difference schemes (cf., e.g., Kreiss and Kreiss [19] or Osher [23]) and the exponentially weighted finite difference and finite element schemes (cf., e.g., Flaherty and Mathon [9] or Hemker[15]). These schemes must usually be elther restricted to relatively simple problems or employ complicated algebraic transformations.

In view of these theoretıcal and computational difficultıes, we simplify problem $(1.1,2)$ consıderably by assuming, in additıon to natural smoothness hypotheses, that (1) $\underset{\sim}{g} \underset{\sim}{a}$ and $\underset{\sim}{b}$ are linear functions of the "fast" varıable $y_{1}(22)$ the $\mathrm{n} \times \mathrm{n}$ Jacobzan

$$
\underset{\sim}{G}(x, t):=\underset{\sim}{g} \underset{\sim}{\sim}(\underset{\sim}{\sim} \underset{\sim}{y}, t, 0)
$$

has a struct hyperbolic splitting with $k>0$ stable and $n-k>0$ unstable eigenvalues for all $x$ and $0<t<1$, and (211) $q>k$ and $r>n-k$. A corresponding theory for problems with quadratic dependence on $\underset{\sim}{y}$ is very lımited (cf., e.g., Howes [17] whıch discusses second-order scalar equatıons). Th1s, of course, lzmsts extension of a numerical theory, but encourages further numerical experimentation.

The assumed hyperbolic spluttıng restricts any rapid variations in $\underset{\sim}{\mathrm{y}}$ to occur in boundary layer regions near $t=0$ and/or 1 . Thus, we unfortunately have eliminated many important and challenglng problems having interzor or "shock" layers. Some numerzcal work on these problems was done 
by Kreiss and Kreıs [19], Osher [23], and O'Malley [22].

In a serzes of three papers, Ascher and Weiss $[2,3,4]$ show that symmetric, or centered, collocation schemes could be used on problems that satısfied assumptions similar to ours provided that appropriately fine meshes were used in the endpoint boundary layers. Our approach is somewhat different in that we use the assumed hyperbolic splittıng to find an asymptotic solution of problem $(1.1,2)$ which is composed of a limzting outer solution $\underset{\sim}{(x}(t)$, $\left.Y_{\sim}(t)\right)$ and boundary layer corrections near $t=0$ and 1 . The limiting solution satisfies a reduced system, which is obtained from (1.1) by formally setting $\varepsilon$ to zero, 1.e.,

$$
\underset{\sim 0}{\dot{X}}=\underset{\sim}{f}(\underset{\sim 0}{X}, Y, t, 0), \quad 0 \underset{\sim}{\sim}=\underset{\sim}{g}(\underset{\sim 0}{X}, \underset{\sim 0}{Y}, t, 0) .
$$

Because $G$ is everywhere nonsingular, we can solve Eq. (1.4b) for $\mathrm{Y}_{0}=\mathrm{Y}_{0}(\mathrm{X}, \mathrm{t})$ In a locally unıque way, and there remains the $\mathrm{m}$ th order differential system $(1.4 a)$ for determining $\underset{\sim 0}{x}(t)$.

In order to completely specify the limiting solutıon, we must prescribe m boundary conditions for Eq. $(1.4 a)$. We do this in section 2 by providing a "cancellation law" that selects a combination of $q-k$ initral condrtions (1.2a) and of $r-n+k$ termanal conditions $(1.2 b)$ to be satisfied by $x_{0}(t)$. For more nonlinear problems, we note that such a cancellation law is much more difficult to specify (cf. O'Malley [21]). Boundary layer corrections are generally needed to compensate for the cancelled instial and terminal conditions, and these are easily determined once $\underset{\sim 0}{X}(t)$ and $\underset{\sim 0}{Y}(t)$ have been found (cf. Section 2).

In Section 3 we discuss a numerıcal procedure for calculating the asymptotic solution of section 2. We Implement the cancellation law by 
using orthogonal transformations to reduce $\underset{\sim}{G} \underset{\sim}{(x}(t), t)$ to a block triangular form with its stable and unstable elgenspaces separated. We also use the general purpose two-point boundary value code CoLSYS to solve the reduced problem and then add numerical approximations of the boundary layer corrections. This approximation is considerably less expensive to obtain than solving the full stiff problem numerically and it has the advantage of Improving in accuracy, without any additional computational cost, as the small parameter $\varepsilon$ tends to zero. However, when $\varepsilon$ is only moderately small, our asymptotic approximation may not be sufficiently accurate for some applications, so we have developed a procedure for generating an improved solution by using COLSYS to solve the complete problem $(1.1,2)$ with our asymptotic approximation as an inztial guess. In order for this approach to succeed, we must also provide COLSYS whth an initial nonuniform mesh that is appropriately graded in the boundary layers, and we give an algorithm for constructing such a mesh in section 3.

In Section 4 we apply our procedures to a third order model problem that has multiple solutions and to problems involving the deformation of a thin nonlinear elastic beam. These examples show that our methods can calculate accurate solutions of stıff problems for a very modest computational effort. While our algorithm for furnishing COLSYS with an inztzal guess and a nonuniform mesh does not seem to be optımal, it does offer some advantages over the more standard approach of continuation in $\varepsilon$, where one starts with a large value of $\varepsilon\left(e_{. g}, \varepsilon=1\right)$ and a crude inttial guess of the solution and reduces $\varepsilon$ in steps so that the mesh is gradually concentrated into the boundary layer regions. 
We also present two examples in Section 4 that are beyond the capabilities of our current methods because their solutions become unbounded as $\varepsilon \rightarrow 0$. We include numerıcal results for these problems in this paper in order to show some of the several challenging effects that can occur with singularly perturbed problems. Finally, in Section 5, we discuss our results and present some suggestions for future investıgations.

\section{Asymptotic Approximation}

with the assumed hyperbolic splitting, we expect solutions of $(1,1,2)$ to feature boundary layers in the fast $\underset{\sim}{\mathrm{y}}$ varzable near both endpoints as $\varepsilon+0$. Thus, it is natural (cf. O'Malley [21]) to seek bounded uniform asymptotic expansions of the form

$$
\left.\begin{array}{l}
\underset{\sim}{\mathrm{x}}(t, \varepsilon)=\underset{\sim}{\mathrm{X}}(t, \varepsilon)+\underset{\sim}{\varepsilon \xi}(\tau, \varepsilon)+\underset{\sim}{\varepsilon \eta}(\sigma, \varepsilon) \\
\underset{\sim}{\mathrm{y}}(t, \varepsilon)=\underset{\sim}{\mathrm{Y}}(t, \varepsilon)+\underset{\sim}{\mu}(\tau, \varepsilon)+\underset{\sim}{\nu}(\sigma, \varepsilon)
\end{array}\right\}, 0<t<1,
$$

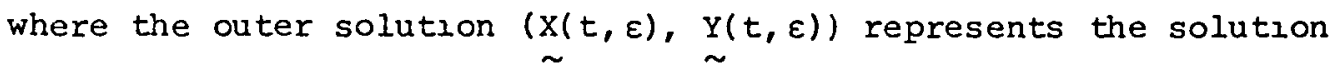
asymptotıcally withın $(0,1)$, the 2 nztzal layer correctıon $(\varepsilon \underset{\sim}{\xi}(\tau, \varepsilon), \underset{\sim}{\mu}(\tau, \varepsilon))$ decays to zero as the stretched variable

$$
\tau=t / \varepsilon
$$




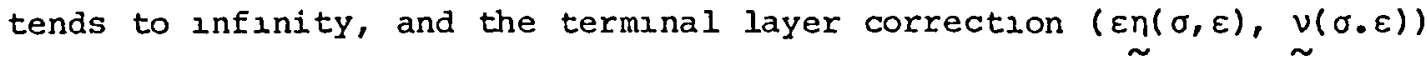
goes to zero as the stretched varıable

$$
\sigma=(1-t) / \varepsilon
$$

approaches infinity. The outer solution and the boundary layer corrections are represented by expanszons of the form

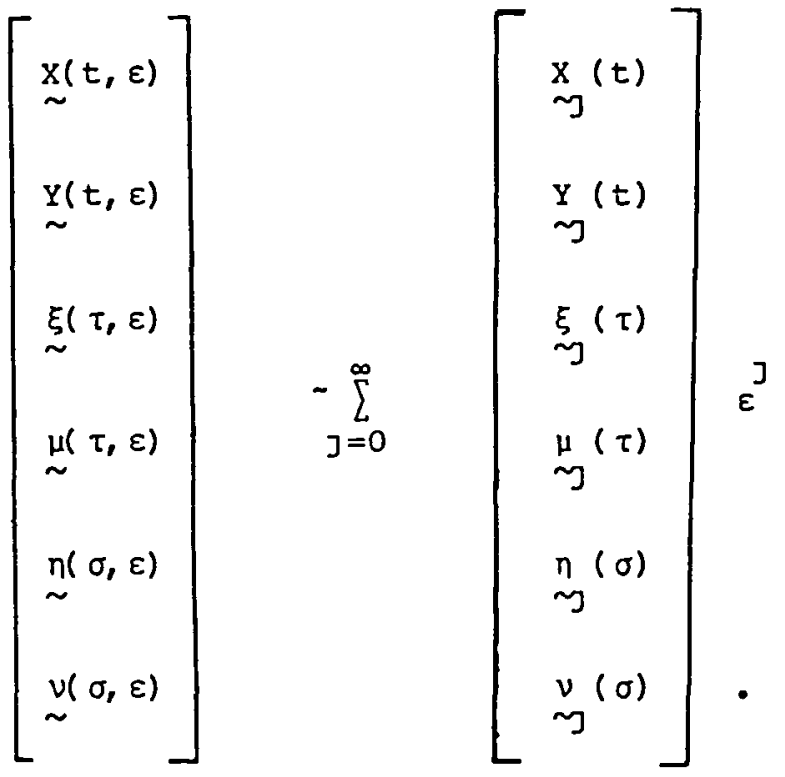

The limitıng uniform approxımation is obtained from $(2.1)$ by letting $\varepsilon$ tend to zero, i.e.,

$$
\underset{\sim}{x}(t, \varepsilon)=\underset{\sim 0}{x}(t)+\underset{\sim}{O}(\varepsilon), \underset{\sim}{\mathrm{y}}(t, \varepsilon)=\underset{\sim 0}{\mathrm{Y}}(t)+\underset{\sim 0}{\mu}(\tau)+\underset{\sim 0}{\sim}(\sigma)+\underset{\sim}{O}(\varepsilon) \cdot
$$

At $t=0$ the fast vector $y$ usually has a discontinuous limit, jumping from $\underset{\sim}{Y}(0,0)=\underset{\sim 0}{Y}(0)+\underset{\sim 0}{\mu}(0)$ to $\underset{\sim 0}{Y}(0)$ at $t=0^{+}$. An analogous Heavisıde discontinuzty generally occurs near $t=1$. 
The outer expansion (2.3a,b) must satisfy the full problem (1.1) within $(0,1)$ as a power series $2 n \varepsilon_{\text {; thus, the }}$ limiting solution $\underset{\sim 0}{(X} \underset{\sim 0}{(Y)}$ will satisfy the nonlinear and non-stiff reduced system (1.4). As previously noted, since $\underset{\sim}{G}\left(x_{\sim}, t\right)$ (cf. Eq. $\left.(1.3)\right)$ is nonsingular we can solve Eq. $(1.4 b)$ for $\mathrm{Y}_{\sim 0}=\mathrm{Y}_{\sim 0}(\mathrm{X}, t)$ in a locally unıque way, so there remains the $\mathrm{m}$ th order nonlinear system $(1.4 a)$ for $\underset{\sim 0}{x}(t)$. Later terms of the expansion $(2.3 a, b)$ satısfy linearized versions of the reduced system. For example, the coefficients of order $\varepsilon$ give

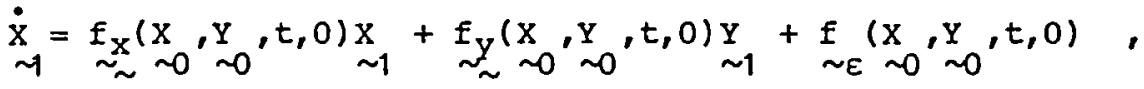

$$
\begin{aligned}
& \left.\underset{\sim 0}{\dot{Y}}=\underset{\sim \sim}{g_{X}}\left(X, \sim_{\sim}, \underset{\sim 0}{Y}, t, 0\right) \underset{\sim 1}{X}+\underset{\sim}{G(X,}, t\right) \underset{\sim 1}{Y}+\underset{\sim \varepsilon}{g}\left(X, \sim_{\sim}^{\prime} \sim \sim_{0}, t, 0\right) .
\end{aligned}
$$

We can determine $\underset{\sim 1}{Y}(t)$ in terms of $\underset{\sim}{X} \underset{\sim 0^{\prime}}{Y}$ and $\underset{\sim 1}{X}$ from $(2.4 b)$ and, once again, there remains the $m$ th order linear system $(2.4 a)$ for $\underset{\sim 1}{x} \cdot S x m z l a r l y$, for each $j>1$, we obtain a system of the form

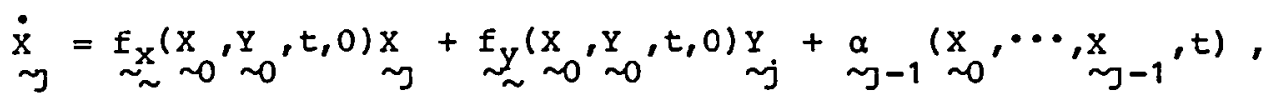

$$
\begin{aligned}
& \left.\underset{\sim-1}{\dot{Y}}=\underset{\sim}{g_{X}}(\underset{\sim 0}{X}, \underset{\sim 0}{Y}, t, 0) \underset{\sim}{X}+\underset{\sim}{G(X,}, t\right) \underset{\sim}{Y}+\underset{\sim}{\beta}(\underset{\sim 0}{X}, \cdots, \underset{\sim J-1}{X}, t)
\end{aligned}
$$

with successively determined inhomogeneous terms. 
In order to completely specify the outer expansion $(2.3 a, b)$, we must prescribe boundary conditions for the m-vectors $\underset{\sim}{x}(t)$. Most critically, we need to specify m boundary conditions for the limiting slow vector $x_{0}(t)$. It is natural to attempt to determine them by somehow selecting a subset of $m$ combinations of the $m+n$ boundary conditzons (1.2) evaluated at $\varepsilon=0$. For scalar hıgher order linear differential equations, the first such "cancellatıon law" was obtained by Wasow [29]. Harrıs [14] obtaıned a more complicated cancellation law for linear systems with coupled boundary conditions and Ferguson [8] developed a numerıcal procedure for corresponding linear problems. These early works suggest that we should seek a cancellation law that ignores an appropriate combination of $k$ initial conditions and of $n-k$ terminal conditions. To this end, we must examine the boundary layer corrections and we begin by considering the instial layer correction $(\varepsilon \underset{\sim}{\xi}, \underset{\sim}{\mu})$. Near $t=0$, the terminal layer correctzon $(\underset{\sim}{n}, \underset{\sim}{\nu})$ may be neglected, so the representation of our asymptotic solution (2.1) requires the initial layer correction $(\underset{\sim}{\varepsilon} \underset{\sim}{\mu})$ to satisfy the nonlinear system

$$
\begin{aligned}
& \mathrm{d} \underset{\sim}{\xi} / \mathrm{d} \tau=\underset{\sim}{\mathrm{dx}} / \mathrm{d} t-\mathrm{dX} / \mathrm{d} t=\underset{\sim}{f}(\underset{\sim}{\mathrm{X}}+\underset{\sim}{\varepsilon}, \underset{\sim}{\mathrm{Y}}+\underset{\sim}{\mu}, \varepsilon \tau, \varepsilon)-\underset{\sim}{\mathrm{f}}(\underset{\sim}{\mathrm{X}}, \underset{\sim}{\mathrm{Y}}, \varepsilon \tau, \varepsilon), \\
& \mathrm{d} \underset{\sim}{\mu / \mathrm{d} \tau} \tau=\varepsilon(\mathrm{dy} / \mathrm{d} t-\mathrm{d} \underset{\sim}{\mathrm{Y}} / \mathrm{d} t)=\underset{\sim}{\mathrm{g}}(\underset{\sim}{\mathrm{X}}+\underset{\sim}{\varepsilon}, \underset{\sim}{\mathrm{Y}}+\underset{\sim}{\mu}, \varepsilon \tau, \varepsilon)-\underset{\sim}{\mathrm{g}}(\underset{\sim}{\mathrm{X}}, \underset{\sim}{\mathrm{Y}}, \varepsilon \tau, \varepsilon),
\end{aligned}
$$

on $\tau>0$ and to decay to zero as $\tau \rightarrow \infty$. Substitutıon of the asymptotzc expansion $(2.3 c, d)$ Into $(2.6)$ provides successive differential equations for the coefficients $(\underset{\sim}{\xi}, \underset{\sim}{\mu})$. In partıcular, when $\varepsilon=0$, we have the limuting instial layer system 


$$
\begin{aligned}
& \mathrm{d} \underset{\sim 0}{\xi} / \mathrm{d} \tau=\underset{\sim}{\mathrm{f}}(\mathrm{X}(0), \underset{\sim 0}{\mathrm{Y}}(0)+\underset{\sim 0}{\mu}, 0,0)-\underset{\sim}{\mathrm{f}}(\underset{\sim 0}{\mathrm{X}}(0), \underset{\sim 0}{\mathrm{Y}}(0), 0,0) \\
& \mathrm{d} \underset{\sim 0}{\mu} / \mathrm{d} \tau=\underset{\sim}{g}(\mathrm{X}(0), \underset{\sim 0}{\mathrm{Y}}(0)+\underset{\sim 0}{\mu}, 0,0)-\underset{\sim}{g} \underset{\sim 0}{\mathrm{I}}(0), \underset{\sim 0}{\mathrm{Y}}(0), 0,0)
\end{aligned}
$$

The decay requirement determınes

$$
{\underset{\sim}{f}}_{0}(\tau)=-\int_{\tau}^{\infty}\left(d \underset{\sim}{\xi_{0}}(s) / d \tau\right) d s
$$

as a functional of $\underset{\sim 0}{\mu}$, while $\underset{\sim 0}{\mu}$ satisfies the conditionally stable system

$$
\underset{\sim 0}{\mu} / \mathrm{d} \tau=\underset{\sim \sim 0}{G(x}(0), 0) \underset{\sim 0}{\mu}
$$

\begin{abstract}
We used (1.3) and the assumed linearzty of $\underset{\sim}{g}$ in $\underset{\sim}{y}$ when obtaining $(2.8 b)$. If $\underset{\sim}{g}(x, y, t, \varepsilon)$ were not linear in $\underset{\sim}{y}$, the initial layer correction would satisfy a nonlinear differential equation which would generally be difficult to solve (cf. O'Malley [21]). Indeed, it would then be extremely difficult to specify what set of initial vectors $\underset{\sim 0}{\mu}(0)$ would lead to decaying solutions of the boundary layer system $(2.7 \mathrm{~b})$. Here, Eq. (2.4) is readily integrated to give
\end{abstract}

$$
\underset{\sim 0}{\mu}(\tau)=e^{G(X(0), 0) \tau} \underset{\sim}{\sim} \underset{0}{\sim}(0) .
$$


Thus, $\underset{\sim}{\mu}$ will decay to zero as $\tau \rightarrow \infty$ provided that

$$
\underset{\sim 0}{\mu}(0)=\underset{\sim}{P} \underset{\sim 0}{P}(0), 0) \underset{\sim 0}{\mu}(0),
$$

where $\mathrm{P}_{\sim}$ is a projection onto the $k$ dimensional stable eigenspace of $\underset{\sim}{G}\left(x_{0}(0), 0\right)$

Substituting (2.10) Into $(1.2 a)$ and letting $\varepsilon+0$, we see that the $q$ limiting inztral condztrons take the form

$$
\underset{\sim}{\mathrm{a}}\left(\mathrm{X}(0), \underset{\sim 0}{\mathrm{Y}}(0)+\underset{\sim}{\mathrm{P}}\left(\mathrm{X}_{\sim}(0), 0\right) \underset{\sim 0}{\mu}(0), 0\right)=\underset{\sim}{0} .
$$

Now, using the linearity of $\underset{\sim}{\sim}$ in $\underset{\sim}{\underset{r}{r}}$ we let

$$
\underset{\sim}{A}(x, t)=\underset{\sim}{a_{\sim}} \underset{\sim}{ }(x, y, t, 0)
$$

and further assume that $\left.\underset{\sim}{A}\left(\mathrm{X}_{\sim}(0), 0\right) \underset{\sim}{\mathrm{P}} \underset{\sim 0}{\mathrm{X}}(0), 0\right)$ has $i t s$ full and maxımal rank $k$. Then we can unıquely determane $\underset{\sim}{\mu}(0)$ as a function of $\underset{\sim 0}{x}(0)$ from $k$ of the equations (2.11). Having done this, initial conditions for the reduced problem can be determined from the remainıng $q-k$ conditions $2 n(2.11)$. For the moment, we write these in the form

$$
\underset{\sim 0}{\Phi(X}(0))=\underset{\sim}{\sim}
$$

In Sectıon 3, we discuss a numerical procedure for determınıng $\underset{\sim}{P}, \underset{\sim}{\mu}(0)$ and $\underset{\sim}{\sim}(x))$ 
The termanal layer correction can be analyzed in an analogous manner. In partıcular, the leading term $\underset{\sim}{\nu}(\sigma)$ satısfies

$$
\nu_{\sim 0}^{\nu}(\sigma)=e^{G(x(1), 1) \sigma} \underset{\sim 0}{\nu} \sim_{0}(0)
$$

Now, $\nu_{0}^{\nu}$ will decay to zero as $\sigma+\infty$ provided that

$$
\left.\nu_{\sim 0}^{\nu}(0)=\underset{\sim}{Q}(x), 1\right) \sim_{\sim 0}^{\nu}(0)
$$

where $\underset{\sim}{Q}$ is a projection onto the $n-k$ dimensional unstable eigenspace of $\underset{\sim}{G(X}(1), 1)$. Substituting $(2.15)$ into $(1.2 b)$ and letting $\varepsilon \rightarrow 0$ grves

the $r$ limiting terminal conditions as

$$
\underset{\sim}{b}\left(x_{0}(1), \underset{\sim 0}{Y}(1)+\underset{\sim}{Q}\left(x_{\sim}(1), 1\right) \underset{\sim 0}{v}(0), 0\right)=0
$$

We let

$$
\underset{\sim}{B}(x, t)=\underset{\sim}{b} \underset{\sim}{\sim}(x, y, t, 0)
$$

and assume that $\left.\underset{\sim}{B}\left(X_{0}(1), 1\right) \underset{\sim}{Q} \underset{\sim}{(X}(1), 1\right)$ has full rank $n-k$. Then we can solve (2.17) for $\nu_{\sim 0}(0)$ and the remainung $r-n+k$ condrtions specify termanal conditions for the limiting problem, which we denote by

$$
\underset{\sim}{\Psi} \underset{\sim 0}{(1)}(1))=\underset{\sim}{0}
$$

The reduced problem consists of the nonlinear reduced differential equation and the $m$ separated nonlinear boundary conditions $(2.13,18)$. If it is solvable, it may have many solutions; however, corresponding to any of Its isolated solutions $\left.\underset{\sim 0}{\left(X_{0}\right.}(t), Y_{0}(t)\right)$, one can expect to find a solution of the orıginal problem $(1.1,2)$ that converges to $\left.\underset{\sim 0}{(X}(t), Y_{0}(t)\right)$ on $0<t<1$ 
as $\varepsilon+0$. Sufficient hypotheses to obtain an asymptotic solution having the form of (2.1) are provided by Hoppensteadt [16] and others. For this reason, we shall merely indicate the considerations that are involved in obtaining further terms in the initial and terminal layer expansions and boundary condrtions for the outer expansion.

Additzonal terms of the initial layer expansion $(2.3 c, d)$ are determined by equating the coefficlents of $\varepsilon^{J}$ in the nonlinear system $(2.7), 1 . e$.

$$
\begin{aligned}
& d \underset{\sim j}{\xi} / d \tau=\underset{\sim}{f} \underset{\sim}{f}(x(0), \underset{\sim 0}{y}(0)+\underset{\sim 0}{\mu}(\tau), 0,0) \underset{\sim}{\mu}+\underset{\sim J-1}{\gamma}(\tau), \\
& d \underset{\sim j}{\mu} / d \tau=\underset{\sim}{G}(x)
\end{aligned}
$$

for $J>1$, where the Inhomogeneous terms are exponentially decaying as $\tau+\infty$ because $\underset{\mathcal{I}-1}{\xi}$ and $\underset{\mathcal{I}-1}{\mu}, 2=1, \ldots, J-1$, and their derivatives behave In this manner. The linear system $(2.19)$ may be integrated to yield

$$
\begin{aligned}
& \underset{\sim}{\xi}(\tau)=-\int_{\tau}^{\infty}(d \underset{\sim}{\xi}(s) / d \tau) d s,
\end{aligned}
$$

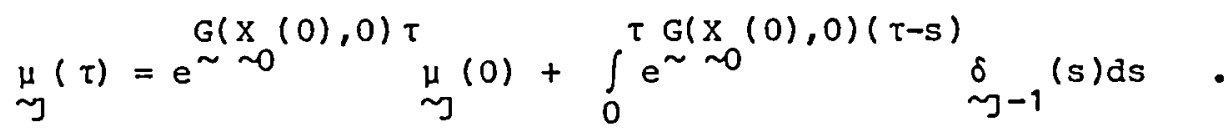

We see that $\underset{\sim}{\xi}(\tau)$ decays as $\tau$ increases and $\underset{\sim}{\mu}(\tau)$ will decay provided that $\underset{\sim}{\mu(0)}$ lies in the unstable elgenspace of $\underset{\sim}{G}\left(x_{\infty}(0), 0\right)$, 1.e.,

$$
\underset{\sim}{\mu}(0)=\underset{\sim}{P}\left(x_{\sim 0}(0), 0\right) \underset{\sim J}{\mu}(0) .
$$


Using $(2.1)$ and $(2.3 a, b)$ we find that the coefficient of $\varepsilon^{J}$ in the initial condition $(1.2 a)$ has the form

$$
\begin{aligned}
& \underset{\sim}{\mathrm{a}_{X}}(\mathrm{X}(0), \underset{\sim 0}{\mathrm{Y}}(0)+\underset{\sim 0}{\mu}(0), 0) \underset{\sim]}{\mathrm{X}}(0)+\underset{\sim}{A}(\mathrm{X}(0), 0) \underset{\sim]}{[\mathrm{Y}}(0) \\
& \left.+\underset{\sim}{P}\left(x_{\sim 0}(0), 0\right) \underset{\sim J}{\mu}(0)\right]=\underset{\sim j-1}{\zeta}
\end{aligned}
$$

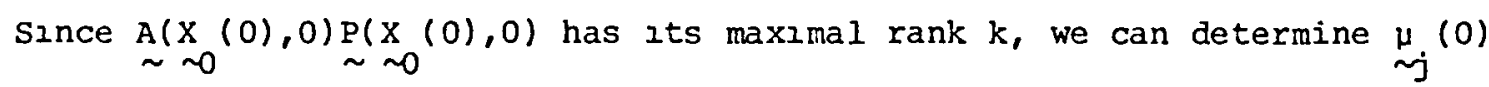
from $k$ of these equations, and the remaznıng $q-k$ equatıons determine linear equations for $x(0)$. The situation for the terminal layer correction is completely analogous; thus, $\underset{\sim}{\nu}(0)$ and the termanal conditions for $\underset{\sim j}{x}(1)$ are determined from linear equations of the form

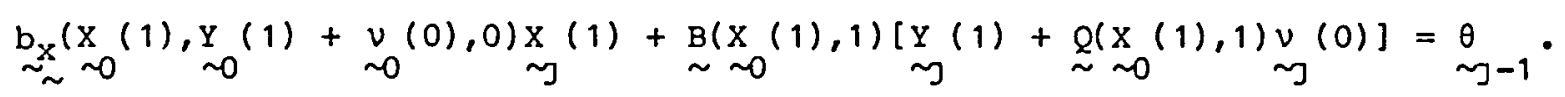

To summarize, we have shown that the $j$ th $(j>1)$ term 1 n the outer expansion satisfies an $m$ th order linear boundary value problem consisting of Eq. (2.5) and a set of $m$ linear boundary conditions determaned from (2.22) and (2.23). It is a linearization of the problem for $x_{0}(t)$. 


\section{Numerical Procedure.}

In this section we discuss a numerıcal procedure for finding the limiting uniform asymptotic solution (2.4). It consists of solving the limiting outer problem $(1.4,2.13,2.18)$ and determınıng boundary layer corrections from (2.9) and (2.14).

Our first task is to find the projections $\underset{\sim}{P}$ and $\underset{\sim}{Q}$ and we do this by finding the schur decomposition of the matrix $\underset{\sim}{G}$ at $t=0$ and $t=1$. In particular, at $t=0$ we find an orthogonal matrix $\underset{\sim}{E} \underset{\sim}{(x}(0), 0)$ such that

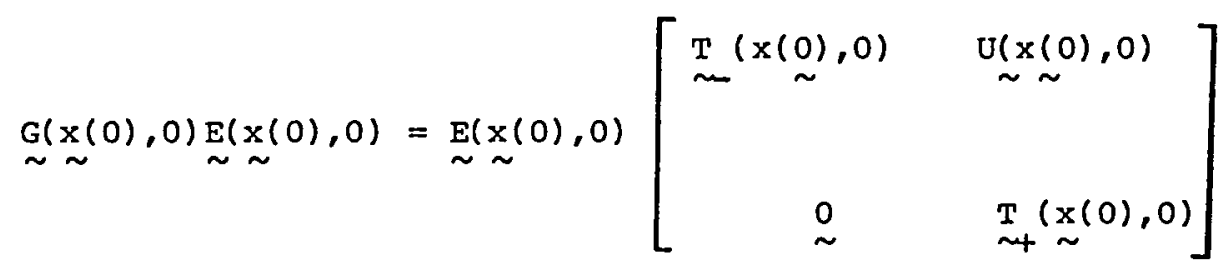

where $T$ is $\mathrm{k} \times \mathrm{k}$ and upper triangular with the stable elgenvalues of

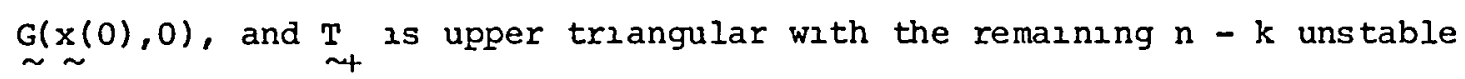
elgenvalues. The decompositzon (3.1) can of ten be obtained analytically; however, when this is not possible or practical it can be determined numerically by using the $Q R$ algorıthm (cf. Golub and wilkinson [13], Ruhe [26], and Bjork [5] for specıflc procedures).

We partition $\underset{\sim}{E}$ after Its $k$ th column as

$$
\underset{\sim}{E}=[\underset{\sim}{E} \bar{E}]
$$

and note that $\underset{\sim}{\mathrm{E}}$ spans the stable ergenspace of $\underset{\sim}{G}$ at $t=0$ and

$$
\underset{\sim}{P}=\underset{\sim}{\mathrm{E}} \stackrel{\mathrm{E}}{\sim}
$$

Is the desired projection onto this exgenspace. 
Substituting (3.3) into (2.11) gives

$$
\underset{\sim}{a}\left(X(0), \underset{\sim 0}{Y}(0)+\underset{\sim}{E}\left(X_{\sim 0}(0), 0\right) \underset{\sim}{E}\left(X_{\sim 0}(0), 0\right) \underset{\sim 0}{\mu_{0}}(0), 0\right)=0 .
$$

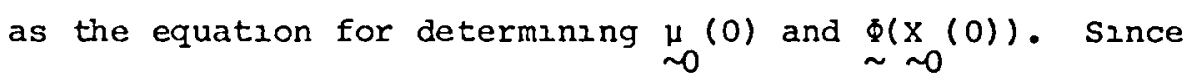

$\underset{\sim}{A}(\underset{\sim 0}{X}(0), 0) \underset{\sim}{E}\left(x_{\sim 0}(0), 0\right)$ is of rank $k$, we construct a $q x q$ matrıx

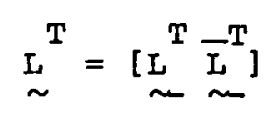

that reduces $2 t$ to echelon form, i.e.,

$$
\left[\begin{array}{l}
L \\
\sim \\
\bar{L} \\
\sim
\end{array}\right] \quad \underset{\sim}{A}(\underset{\sim 0}{x}(0), 0) \underset{\sim 0}{E}\left(x_{\sim 0}(0), 0\right)=\left[\begin{array}{l}
V \\
\sim \\
0 \\
\sim
\end{array}\right],
$$

where $\mathrm{V}$ is $\mathrm{k} \times \mathrm{k}$ and nonsingular. Multiplying Eq. (3.4) by $\mathrm{L}_{\sim}$, using the linearlty of $\underset{\sim}{a}$ in $\underset{\sim}{\mathrm{y}}$, and Eq. (3.5) gives the 1 nitial layer jump $\underset{\sim 0}{\mu}(0)$ and the $q-k$ inltial conditions (2.13) for the reduced problem, respectively, as

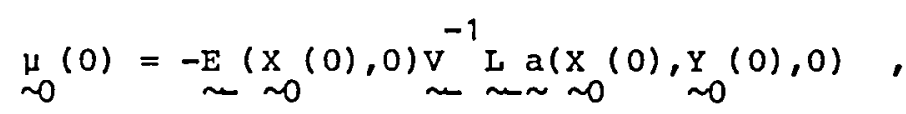

$$
\begin{aligned}
& \left.\underset{\sim}{\Phi} \underset{\sim 0}{X}(0)):=\operatorname{L}_{\sim \sim}^{\bar{a}} \underset{\sim}{ }(X),{\underset{\sim 0}{Y}}_{0}(0), 0\right)=\underset{\sim}{0} .
\end{aligned}
$$

We find the terminal layer jump and the $r-(n-k)$ terminal conditions for the reduced problem in an analogous fashion with the exception that we define $\underset{\sim}{E}(x(1), 1)$ such that 


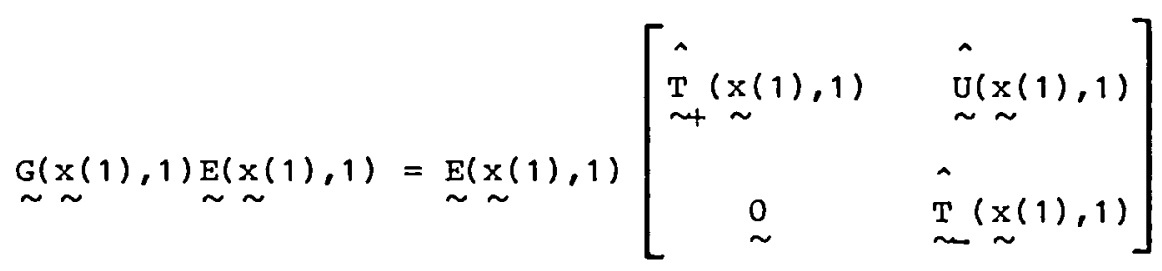

which we partztzon after its $(n-k)$ th column as

$$
\underset{\sim}{E}=\left[\begin{array}{ll}
E & \bar{E}
\end{array}\right]
$$

In parallel wıth Eqs. (3.1) and (3.2), the matrices $\stackrel{\wedge}{\mathrm{T}}, \stackrel{\hat{T}}{\sim}$, and $\underset{\sim}{\mathrm{E}}$ contain the $k$ stable elgenvalues, the $n-k$ unstable eigenvalues, and span the unstable eigenspace, respectively, of $\underset{\sim}{G}$ at $t=1$. Our reasons for switching the positions of the matrices contalning the stable and unstable elgenvalues of $G$ is that we are unaware of a simple and stable computational procedure for finding a set of vectors that span a given subspace and are not in the leading columns of an orthogonal matrix like $\underset{\sim}{\mathrm{E}}$ (cf. Golub and Wilkinson [13]). Now, following the procedure that we used for the initial layer, we take

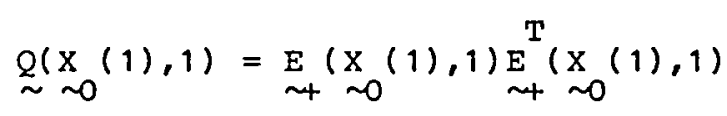

as our projection onto the $(n-k)$ dimensional unstable eigenspace of $\underset{\sim}{G(x}(1), 1)$ and construct an $r \times r$ matrıx

$$
\left.\mathrm{R}_{\sim}^{\mathrm{T}}=\underset{\sim \mathrm{R}}{\mathrm{T}} \underset{\sim \mathrm{R}}{\mathrm{T}}\right]
$$

that reduces the rank $n-k \operatorname{matr} \perp x \underset{\sim \sim 0}{B}(\underset{\sim}{X}(1), 1) \underset{\sim}{E}(\underset{\sim 0}{X}(1), 1)$ to echelon form, 1.e.,

$$
\left.\left[\begin{array}{l}
R \\
\sim+ \\
\bar{R} \\
\sim
\end{array}\right] \underset{\sim \sim 0}{B(x}(1), 1\right) \underset{\sim \sim}{\mathrm{E}}(\underset{\sim 0}{\sim}(1), 1)=\left[\begin{array}{l}
V \\
\sim+ \\
0 \\
\sim
\end{array}\right]
$$


where $V_{\sim}$ is $(n-k) \times(n-k)$ and nonsingular. Multiplying Eq. (2.16) by $\underset{\sim}{R}$ and usıng Eqs. (3.9) and (3.10), we find the terminal layex jump and terminal conditions for the reduced problem, respectively, as

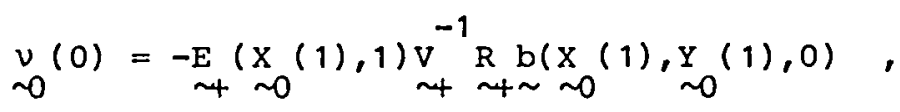

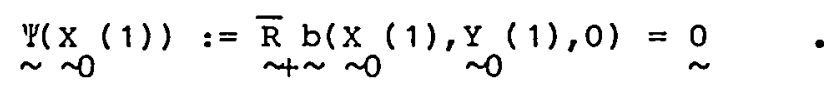

Since the reduced problem $(1.4),(3.6 \mathrm{~b})$, and $(3.11 \mathrm{~b})$ is not stiff, we can use any good code for two-point boundary value problems (cf. Chrlds et al. [6]) to solve It, and we have chosen to use the collocation code Colsys of Ascher, Christiansen, and Russell [1]. The reduced problem is generally non linear and since COLSYS solves nonlinear problems using a damped Newton method, we have to supply formulas for evaluatıng the Jacobıans of $\underset{\sim}{\sim} \underset{\sim}{\Psi} \underset{\sim}{,}$ and $\underset{\sim}{\Psi}$ wath respect to $\underset{\sim}{x}$ We do this, but introduce an error, by providing analytical formulas for these Jacobıans that neglect the influence of the derivatives of $\underset{\sim}{E} \underset{\sim}{L} \underset{\sim}{R}$ and $\underset{\sim}{\sim}$ (These derzvatives wIll be small when the related subspaces are nearly constant). This procedure falled to converge once on Example 1 of Section 4 and a manor modification to the Jacobian of $\Phi$ restored convergence; however, an alternative possibility would be to approximate the Jacobıans by finıte differences.

We start the Newton iteration with a uniform mesh and an initial guess $x_{0}^{(0)}(t)$ for $x_{\rightarrow}(t)$. In section 4 , we used the default instial guess that is provided by CoLsys for Example 2 and a constant 2 nitial guess for Example 1 . 
Th1s latter cholce was necessary as Example 1 has three solutions. At each iteration step, we calculate an approximation $\left.\underset{\sim}{\operatorname{E}\left(X_{\sim}^{X}\right.}(p)(t), t\right)$ to $\underset{\sim}{E} \underset{\sim}{(X(t), t)}$ for $t=0$ and 1 as the schur decomposition of $\left.\underset{\sim}{G(x}{ }^{(p)}(t), t\right)$. The examples of Section 4 were calculated using analytıcal formulas for $\mathrm{E}$ rather than the numerlcal procedures of Golub and Wilkinson [13], Ruhe [26], or Bjork [5]. Finally, $\underset{\sim}{(p)}$ and $\underset{\sim}{(p)}$ are obtained by using Gaussian Elimination to row reduce $\underset{\sim}{A}\left(x_{\sim}^{(p)}(0), 0\right) \underset{\sim}{\mathrm{E}}\left(\mathrm{x}_{\sim 0}^{(p)}(0), 0\right)$ and $\left.\underset{\sim}{\mathrm{B}\left(\mathrm{x}_{\sim 0}^{(p)}\right.}(1), 1\right) \underset{\sim}{\mathrm{E}}\left(\mathrm{x}_{\sim 0}^{(p)}(1), 1\right)$, respectively.

When this procedure converges to $\left.\underset{\sim 0}{\mathrm{X}}(t), \sim_{0}^{\mathrm{Y}}(t)\right)$, we calculate boundary layer corrections $\sim_{0}^{\mu}(\tau)$ and $\nu_{\sim}^{\nu}(\sigma)$, for a given value of $\varepsilon$, using Eqs. (2.9). (3.6a), (2.14), and (3.11a), and add these to the reduced solution in order to get the $O(\varepsilon)$ asymptotic approximation $(1.4)$. For moderately small values of $\varepsilon$, this approximation may not provide a sufficiently accurate representation of the solution and, in this case, we use it as an inztial guess to Colsys and solve the complete problem $(1.1,2)$. However, this procedure may fall unless we also provide COLSYS with an inztial nonuniform partition

$$
\pi:=\left\{0=t_{0}<t_{1}<\cdots<t_{N}=1\right\}
$$

that is appropriately graded within the boundary layers. Following Ascher, Christransen, and Russell [1], we seek to find $\pi$ such that the error on each subinterval satisfies

$$
\|\underset{\sim}{\mathrm{e}}\|_{1}<\delta\left(1+\|\underset{\sim}{\mathrm{u}}\|_{2}\right), \quad 1=1,2, \ldots, \mathrm{N},
$$


where $\delta$ is a prescribed tolerance,

$$
\underset{\sim}{\mathrm{u}}=\left[\mathrm{x}_{\sim}^{\mathrm{T}}, \underset{\sim}{\mathrm{y}} \mathrm{T}\right]
$$

$\underset{\sim}{e(t)}$ is the difference between $\underset{\sim}{u}(t)$ and 1 ts collocation approximation,

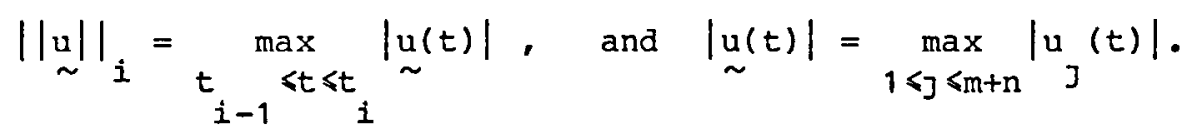

We assume that the final partition selected by COLSYS to solve the reduced problem satisfies (3.13) outside of boundary layer regions and we seek to refine it within the boundary layers. We further assume that derivatives of $\underset{\sim}{u}$ can adequately be approximated by either $\underset{\sim 0}{\mu}(\tau)$ or $\underset{\sim 0}{\nu}(\sigma)$ in the left or right boundary layer, respectıvely.

It is known (cf. Russell and Christiansen [27]) that if the solution of $(1,1,2)$ is smooth

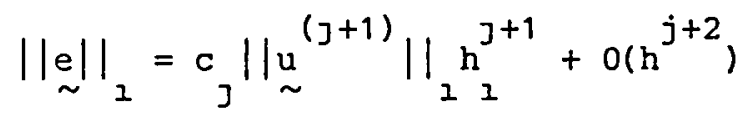

for collocation at the 1mage of J Gauss-Legendre points per subinterval. Here $c_{j}$ is a known constant,

$$
h_{1}=t_{1}-t_{1-1} \text {, and } h=\max _{1 \leqslant 1 \leqslant N} h_{i} \cdot
$$

In the left boundary layer we approximate $\underset{\sim}{u}$ in (3.16) by ${ }_{\sim}^{\mu}$ using (2.9) and attempt to find a partition that satısfies

$$
c_{J 2} h^{J+1}\left\|\mu_{\sim 0}^{(J+1)}(t / \varepsilon)\right\|_{2} \approx \delta\left(1+\|u\|_{2}\right)
$$


Finally, we use $(2.9)$ and $(3.1)$ to approximate $\underset{\sim}{\mu}$ and the subinterval lengths as

$$
t_{1}-t_{1-1} \approx \underset{\alpha}{\varepsilon}\left[\frac{\delta\left(1+\|\underset{\sim}{u}\|_{1}\right)}{\underset{j}{c_{\sim 0} \underset{\sim}{\mid}\left(t_{2-1} / \varepsilon\right) \mid}}\right]^{1 /(j+1)}
$$

where $\alpha_{2}$ is the magnitude of the largest diagonal element of $T(x(0), 0)$. A sımilar formula can be obtained for selecting subıntervals in the right boundary layer.

Starting with $1=1$, we use Eq. (3.19) to generate a partition until we elther reach $t=1 / 2$ or a point where a subinterval length selected by Eq. (3.19) is larger than that used locally by COLSYS to solve the reduced problem. We then repeat the procedure in the raght boundary layer. We have written a computer code called SPCOL that implements the aigorithms that are described in this section; thus, it (1) uses COLSYS to solve the reduced problem, (11) calculates and adds appropriate boundary layer corrections to the reduced problem, and (2i1) (optzonally) suggests a mesh that can be used by CoLsys to solve the complete problem.

\section{Examples.}

In order to appraise the performance of SPCOL, we have applied it to a problem involving the deformation of a thin nonlinear elastic beam (Example 1) and a third order model problem that has multiple solutions (Example 2). 
Example 1. We consider problems involving the deformation of a nonlınear elastic beam that is resting on an elastic foundation with unit spring constant and is subjected to the combined action of a horizontal end thrust $P$ and a unit uniform lateral load. This problem is discussed in detail in Flaherty and O'Malley [11] and hereln we only present the governing differential equations, which in dimensionless form are

$$
\begin{aligned}
& \dot{x}_{1}=\cos x_{3}, \quad \dot{x}_{2}=\sin x_{3}, \quad \dot{x}_{3}=y_{1}, \quad(4.1 a, b, c) \\
& \dot{\varepsilon y}_{1}=-y_{2}, \quad \dot{y}_{2}=\left(x_{2}-1\right) \cos x_{3}-T y_{1},
\end{aligned}
$$

where

$$
T=\sec x_{3}+\varepsilon_{2} \tan x_{3}
$$

The slow variables $\left(x_{1}, x_{2}\right)$ and $x_{3}$ represent the Cartesian coordinates and the tangent angle of a material particle on the centerline of the beam that was at the Cartesian location $(t, 0)$ in the undeformed state. The fast variables $y_{1}$ and $y_{2}$ are the internal bending moment and transverse shear force, respectively. Finally, the small parameter is

$$
\varepsilon^{2}=\mathrm{EI} / \mathrm{PL}{ }^{2}
$$

where EI Is the flexural rigidity and $L$ is the length of the beam; thus, our beam is much stronger in extension than it is in bending. 
This example does not precisely fit our hypotheses since the axial force $T$ is a function of the fast variable $y_{2}$ and, thus, $\underset{\sim}{g}$ also depends on $\underset{\sim}{\mathrm{y}}$. However, our theory and methods will still apply as long as $\underset{\sim}{\mathrm{Y}}$ remains bounded and $\left|x_{3}\right|<\pi / 2$ as $\varepsilon+0$. Flaherty and O'Malley [11] show that unbounded solutions can occur when certaln types of boundary condltions are prescribed for Eq. (4.1). In this paper we present results for the following three sets of boundary conditions:

(1). $\quad x_{1}(0, \varepsilon)=x_{2}(0, \varepsilon)=y_{1}(0, \varepsilon)=x_{2}(1, \varepsilon)=y_{1}(1, \varepsilon)=0$,

(i2).

$$
\begin{array}{r}
x_{1}(0, \varepsilon)=0,-\frac{10 x_{2}(0, \varepsilon)+y_{2}(0, \varepsilon)}{}=0,-x_{3}(0, \varepsilon)+10 y_{1}(0, \varepsilon)=0 \\
10 x_{2}(1, \varepsilon)+y_{2}(1, \varepsilon)=0,10 x_{3}(1, \varepsilon)+y_{1}(1, \varepsilon)=0,
\end{array}
$$

(121). $\mathrm{x}_{1}(0, \varepsilon)=\mathrm{x}_{2}(0, \varepsilon)=\mathrm{x}_{3}(0, \varepsilon)=\mathrm{x}_{2}(1, \varepsilon)=\mathrm{x}_{3}(1, \varepsilon)=0$.

Equations (4.2a) correspond to "simple supports", Eqs. (4.2c) correspond to "clamped supports", and Eqs. (4.2b) correspond to elastzc supports that are almost simply supported at $t=0$ and almost clamped at $t=1$. Conditions (4.2b) could arıse because, say, friction introduces some coupling between lateral and rotational effects at the supports. As we shall see, $\underset{\sim}{y}$ remains bounded for conditions $(4.2 \mathrm{a}, \mathrm{b})$, but becomes unbounded as $\varepsilon \rightarrow 0$ when conditions (4.2c) are applied. The problem is that the boundary conditions for the clamped beam only involve the slow variables and the slow vector $\mathbf{x}$ cannot generally satisfy all five of them without having boundary layers. This in turn forces the fast vector $\underset{\sim}{\mathrm{y}}$ to become unbounded like $O(I / \varepsilon)$ at 
the endpoints. Thus, the solutzon cannot have an asymptotic expansion of the form of Eq. (2.1); however, an appropriate asymptotzc expansion was obtalned by Flaherty and O'Malley [11]. We do not repeat those results here, but in order to emphasize the diverse behavior that can occur with nonlinear singularly perturbed problems, we present solutions for $x_{2}, x_{3}$, and $Y_{3}$ corresponding to each of the boundary condltions $(4.2 \mathrm{a}),(4.2 \mathrm{~b})$, and (4.2c) In Figures 1, 2, and 3, respectively.

Our methods apply to problems having boundary condztzons (4.2a) and (4.2b) and, in these cases, the orthogonal matrix

$$
\underset{\sim}{E(x(0), 0)}=(1+\alpha)^{2}-1 / 2\left[\begin{array}{cc}
1 & -|\alpha| \\
|\alpha| & 1
\end{array}\right]
$$

where

$$
\alpha^{2}=\sec x_{3}(0)
$$

reduces

$$
\underset{\sim}{G}(x), 0)=\left[\begin{array}{cc}
0 & -1 \\
2 & 0
\end{array}\right]
$$

to the schur form glven by $(3.1)$ at $t=0$ whlle $\underset{\sim}{E} \underset{\sim}{\mathrm{T}}(x(1), 1)$ will reduce $\underset{\sim}{G}(x(1), 1)$ to the form given by $(3.7)$ at $t=1$

We solved Eq. (4.1) with condztıons (4.2a) and (4.2b) in two ways: (1) using colsys to solve the complete problem with continuation from a large 
24.
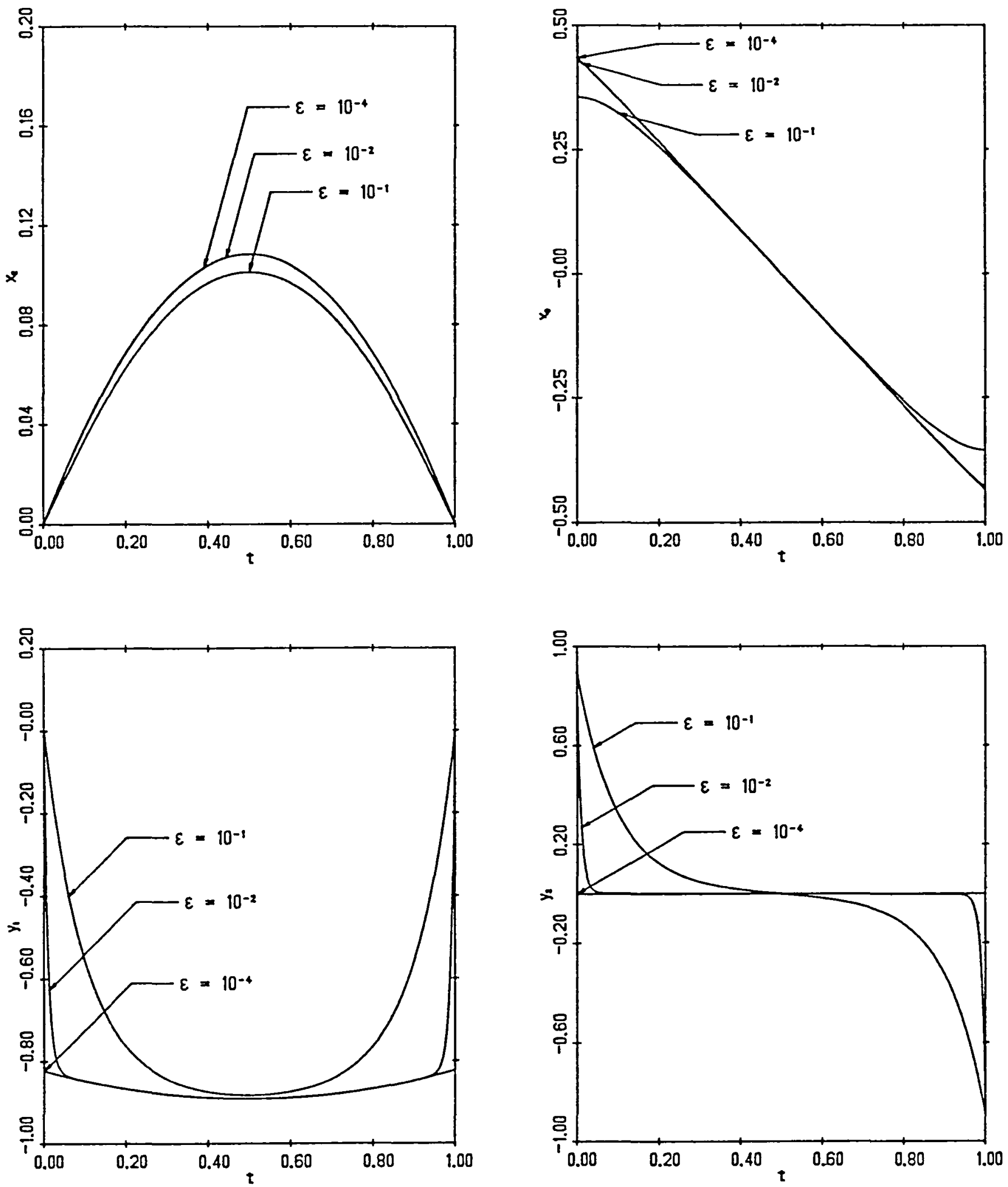

Figure 1. Numerical solution of simply supported beam, Example 1 with boundary conditions given by equation ( $4.2 a)$. 
25.
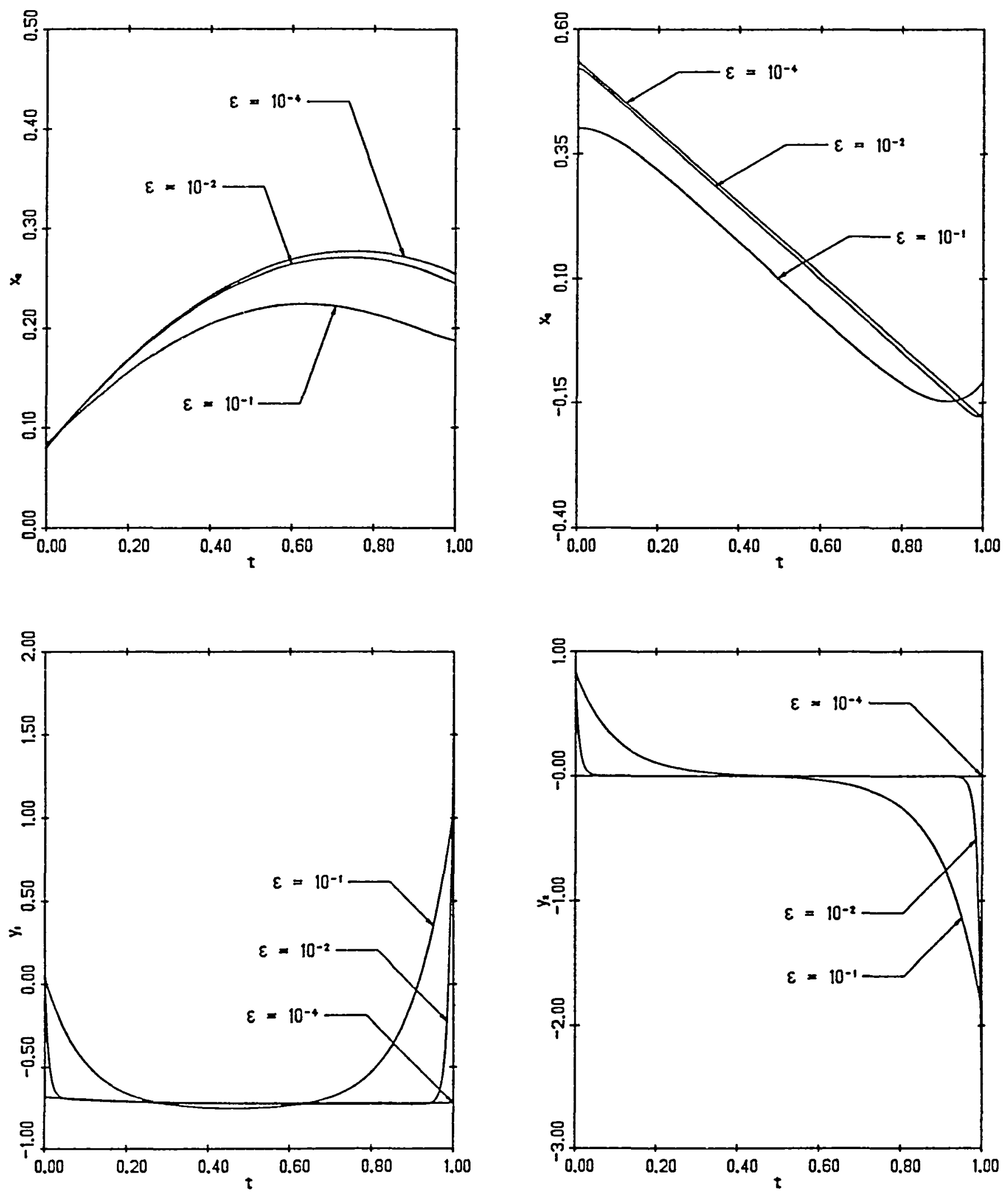

Figure 2. Numerical solution of elastically supported beam, Example I wIth boundary conditions given by equation (4.2b). 
26.
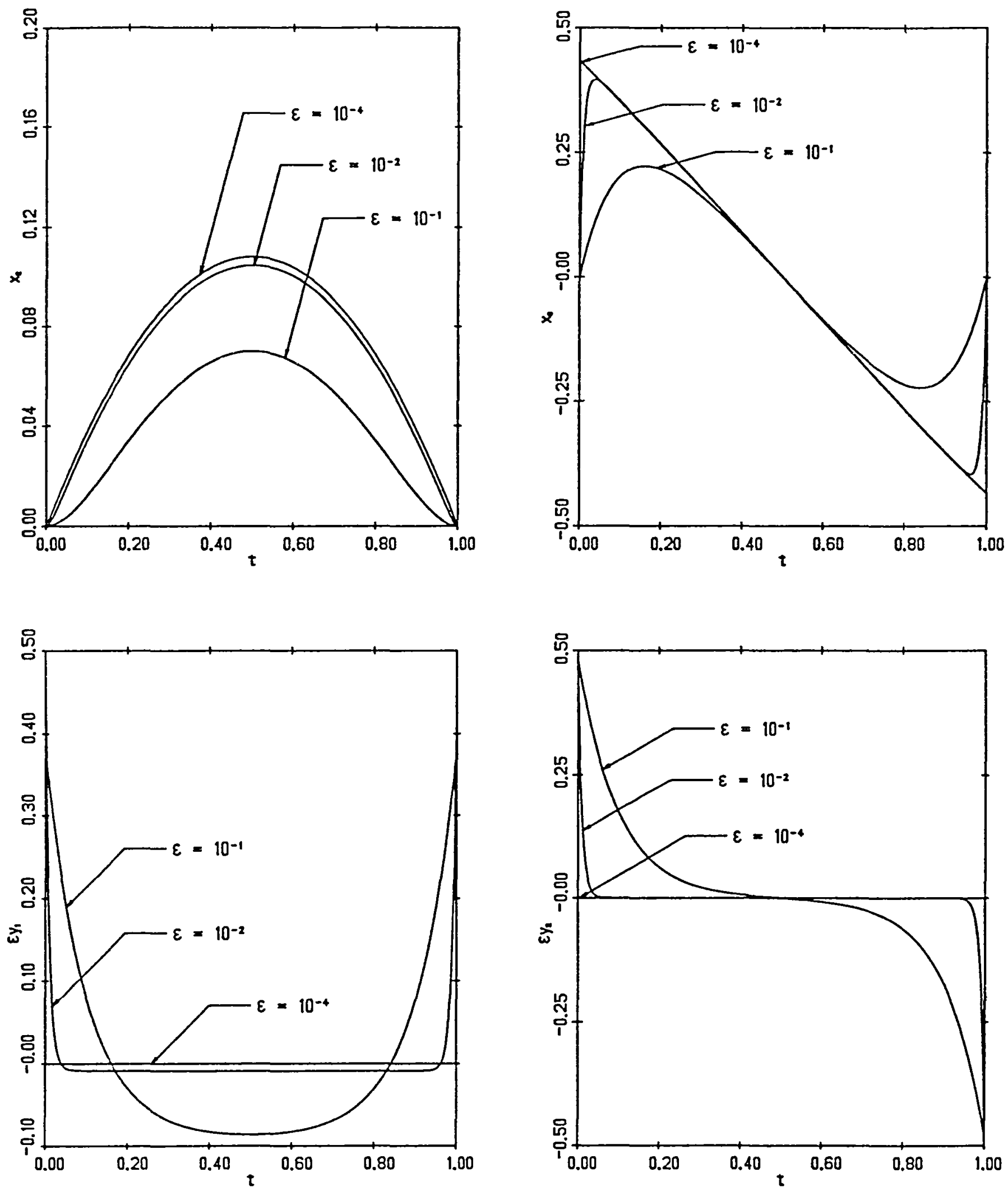

Figure 3. Numerical solution of clamped beam, Example 1 with boundary conditions given by equation $(4.2 c)$. Note that $y_{1}$ and $y_{2}$
are multiplied by $\varepsilon$. 
to a small value of $\varepsilon$ and (11) using our code spcol to compute an initial asymptotıc approximation and to recommend a nonuniform mesh and using this with COLSYS to calculate an improved solution. All calculations were performed using double precision arithmetic on an IBM 3033 computer, two collocation points per subınterval, and an error tolerance $\delta$ (cf. Eq. (3.19)) of $10^{-6}$ for slow variables and $10^{-3}$ for fast variables. Our results for the normalized $C P$ times and the number of subintervals (NSUB) that are either used by COLSYS or recommended by SPCOL are shown in Tables 1 and 2 for the simply supported beam and in Tables 3 and 4 for the elastıcally supported beam. Tables 1 and 3 contain the continuation results and Tables 2 and 4 contain the sPCOL results with CoLsYs Improvement. The CP tImes (for all examples) were normalized with respect to the $\varepsilon$ sequence in Table i. Differences between our Inltial asymptotic approximation and the final solution obtained by COLSYS are shown for $x_{2}(1 / 2, \varepsilon)$ and $y(0, \varepsilon)$ for the simply supported beam in Table 5 and for $x_{3}(0, \varepsilon)$ and $y_{2}(0, \varepsilon)$ for the elastıcally supported beam in Table 6. All of the differences are decreasing like $O(\varepsilon)$ as expected. Differences that are recorded as zero are less than $10^{-8}$

The results reported in these Tables need some additional explanation. The number of subintervals and $C P$ times used with continuation depended heavily on the $\varepsilon$ sequence that was used. The results in Tables 1 and 3 are about the best insofar as they gave the smallest total CP tame for the sequence. We see in almost every instance that the CoLSYS correction is using about twice the number of sublntervals that were suggested by SPCOL. This mesh doubling strategy is often used in COLSYS to estimate errors or when the Newton iteration has convergence difficulties. Thus, in some sense our mesh 


\begin{tabular}{|c|c|c|c|}
\hline$\varepsilon$ & NSUB & CP & TOTAL CP \\
\hline $10^{-1}$ & 80 & 6.1 & 6.1 \\
$10^{-2}$ & 72 & 6.3 & 12.5 \\
$10^{-4}$ & 112 & 18.4 & 30.9 \\
$10^{-8}$ & 158 & 27.2 & 58.1 \\
\hline
\end{tabular}

TABLE 1. EXAMPLE 1 WITH SIMPLE SUPPORTS. NUMBER OF SUBINTERVALS (NSUB) AND CP TIMES TO SOLVE THE PROBLEM BY COLSYS WITH CONTINUATION IN $\varepsilon$. TOTAL CP IS THE ACCUMULATED TIME FOR THE $\varepsilon$ SEQUENCE.

\begin{tabular}{|c|c|c|c|c|c|}
\hline$\varepsilon$ & \multicolumn{3}{|c|}{ SPCOL } & \multicolumn{2}{c|}{$\begin{array}{c}\text { COLSYS } \\
\text { CORRECTION }\end{array}$} \\
\cline { 2 - 6 } & NSUB & CP & NSUB & CP & TOTAL CP \\
\hline $10^{-1}$ & 20 & 1.3 & 80 & 5.7 & 7.0 \\
$10^{-2}$ & 28 & 1.3 & 112 & 8.7 & 10.0 \\
$10^{-4}$ & 34 & 1.3 & 136 & 9.0 & 10.3 \\
$10^{-8}$ & 35 & 1.3 & 92 & 9.3 & 10.6 \\
\hline
\end{tabular}

TABLE 2. EXAMPLE 1 WITH SIMPLE SUPPORTS. NUMBER OF SUBINTERVALS (NSUB) AND CP TIMES TO SOLVE THE PROBLEM BY SPCOL AND TO IMPROVE IT BY COLSYS. THE CP TIMES INCLUDE THE TIME TO CALCULATE THE REDUCED SOLUTION, WHICH WAS 1.3 TIME UNITS. TOTAL CP IS THE SUM OF THE SPCOL CP AND THE COLSYS CP. 


\begin{tabular}{|l|c|c|c|}
\hline$\varepsilon$ & NSUB & CP & TOTAL CP \\
\hline $10^{-1}$ & 80 & 6.9 & 6.9 \\
$10^{-2}$ & 78 & 6.3 & 14.6 \\
$10^{-4}$ & 78 & 16.8 & 31.4 \\
$10^{-6}$ & 156 & 38.3 & 69.7 \\
$10^{-8}$ & 100 & 16.4 & 86.1 \\
\hline
\end{tabular}

TABLE 3. EXAMPLE 1 WITH ELASTIC SUPPORTS. NUMBER OF SUBINTERVALS (NSUB) AND CP TIMES TO SOLVE THE PROBLEM BY COLSYS WITH CONTINUATION IN $\varepsilon$. TOTAL CP IS THE ACCUMULATED TIME FOR THE $\varepsilon$ SEQUENCE.

\begin{tabular}{|c|c|c|c|c|c|}
\hline \multirow{2}{*}{$\varepsilon$} & \multicolumn{2}{|c|}{ SPCOL } & \multicolumn{2}{c|}{$\begin{array}{c}\text { COLSYS } \\
\text { CORRECTION }\end{array}$} \\
\cline { 2 - 5 } & NSUB & CP & NSUB & CP & TOTAL CP \\
\hline $10^{-1}$ & 40 & 3.9 & 100 & 10.2 & 14.1 \\
$10^{-2}$ & 47 & 3.9 & 94 & 10.5 & 14.4 \\
$10^{-4}$ & 56 & 3.9 & 112 & 12.8 & 16.7 \\
$10^{-8}$ & 57 & 3.9 & 134 & 16.8 & 20.7 \\
\hline
\end{tabular}

TABLE 4. EXAMPLE 1 WITH ELASTIC SUPPORTS. NUMBER OF SUBINTERVALS (NSUB) AND CP TIMES TO SOLVE THE PROBLEM BY SPCOL AND TO IMPROVE IT BY COLSYS. THE CP TIMES INCLUDE THE TIME TO CALCULATE THE REDUCED SOLUTION, WHICH WAS 3.8 TIME UNITS. TOTAL CP IS THE SUM OF THE SPCOL CP AND THE COLSYS CP. 


\begin{tabular}{|c|c|c|}
\hline$\varepsilon$ & $\Delta x_{2}(1 / 2, \varepsilon)$ & $\Delta y_{2}(0, \varepsilon)$ \\
$10^{-1}$ & $7.1 \times 10^{-3}$ & $3.2 \times 10^{-2}$ \\
$10^{-2}$ & $6.7 \times 10^{-5}$ & $3.6 \times 10^{-3}$ \\
$10^{-4}$ & 0 & $3.6 \times 10^{-5}$ \\
$10^{-8}$ & 0 & 0 \\
\hline
\end{tabular}

TABLE 5. EXAMPLE 1 WITH SIMPLE SUPPORTS. DIFFERENCES BETWEEN SPCOL AND COLSYS SOLUTIONS, 1.e., $\Delta l):=\mid($ ) SPCOL - ( ) COLSYSl.

\begin{tabular}{|c|c|c|}
\hline$\varepsilon$ & $\Delta_{3}(0, \varepsilon)$ & $\Delta y_{2}(0, \varepsilon)$ \\
$10^{-1}$ & $1.3 \times 10^{-1}$ & $4.2 \times 10^{-2}$ \\
$10^{-2}$ & $1.4 \times 10^{-2}$ & $5.2 \times 10^{-3}$ \\
$10^{-4}$ & $1.5 \times 10^{-4}$ & $5.4 \times 10^{-5}$ \\
$10^{-8}$ & 0 & 0 \\
\hline
\end{tabular}

TABLE 6. EXAMPLE 1 WITH ELASTIC SUPPORTS. DIFFERENCES BETWEEN SPCOL AND COLSYS SOLUTIONS, 1.e., $\Delta l):=\mid()_{\text {SPCOL }}$ - $($ icolsysl. 
strategy is dolng about as well as can be expected; however, it seems that fewer points should be necessary. We trıed placing the subintervals according to a pointwıse error crıterıa, as suggested by Ascher and Weiss [2, 3, 4], rather than the global criterıa used in Eq. (3.19), but this gave very simular results (cf. Flaherty and o'Malley [12]). We also trıed suggestıng an inıtzal mesh to COLSYS that consisted of every other polnt in the mesh suggested by SPCOL. This is clearly a risky strategy, since collocation at the Gauss-Legendre pounts is known to produce osclllations unless the mesh is appropriately fine in the boundary layers (cf. Ascher and Welss [21). Nevertheless, this did give some improvement for values of $\varepsilon>10^{-8}$ (cf. Flaherty and O'Malley (12]). Perhaps the results could be improved further by using higher order collocation and/or collocation at the Gauss-Lobatto points as suggested by Ascher and Werss $[2,3,4]$. We see from Tables 1 to 4 that for $\varepsilon=10^{-8}$ the SPCOL solution can be computed in less than $5 \%$ of the time of the contanuation solution and the COLSYS Improvement with the SPCOL solution as an initial guess can be computed in less than 248 of the tzme of the continuation solution for both simple and elastic supports.

Example 2. We consider the third order model problem

$$
\dot{x}=1-x, \quad \quad \dot{y}_{1}=y_{2}, \quad \quad \dot{y}_{2}=\alpha^{2}(x) y_{1}+8 x(1-x) \quad(4.5 a, b, c)
$$

with

$$
\alpha(x)=1+2 x
$$


and the linear boundary conditions

$x(0, \varepsilon)+y_{1}(0, \varepsilon)=0,-y x(0, \varepsilon)+y_{2}(0, \varepsilon)=0, \quad x(1, \varepsilon)+y_{1}(1, \varepsilon)=0$.

The matrıx $G(x, t)$ for this example is the negative of that given by (4.4) for Example 1 wath a now being given by (4.5d). Thus, $G$ has one negative and one positive elgenvalue provided that $\alpha(x)$ is nonzero and $G$ may be reduced to Schur form at $t=0$ using the orthogonal matrix $\underset{\sim}{\mathrm{E}} \underset{\sim}{\mathrm{T}}(\underset{\sim}{\mathrm{x}}(0), \underset{\sim}{0})$ and at $t=1$ using $\underset{\sim}{E}(x(1), 1) \quad($ wath $\underset{\sim}{E}(x, t)$ glven by $E q .(4 \cdot 3 a))$.

Flaherty and O'Malley [10] studied this problem and showed that the reduced system is

$$
\dot{x}_{0}=1-x_{0}, \quad y_{20}=0, \quad \alpha^{2}\left(x_{0}\right) y_{10}+8 x_{0}\left(1-x_{0}\right)=0
$$

with the initial condition

$$
\left|\alpha\left(X_{0}(0)\right)\right|\left[X_{0}(0)+Y_{10}(0)\right]-\gamma X_{0}(0)=0
$$

They show that there are three solutions of $(4.7,8)$ for each value of the constant $\gamma$ provided that there are no "turning points", i.e., provided that there are no values of $x(t)$ for which $\alpha(x)=0$ on $0<t<1$. The three solutzons can be characterzzed by their value of $x_{0}(0)$ which is determined as

$$
x_{0}(0)=0, \frac{1}{4}\left[\gamma s-6 \pm \sqrt{(\gamma s-4)^{2}+48}\right], s=\operatorname{sgn}\left(\alpha\left(x_{0}(0)\right) .\right.
$$


For $\gamma=2$ the three values of $x_{0}(0)$ are $0,0.803$, and -4.29 and the three corresponding solutions for $\mathrm{y}_{1}(t, \varepsilon)$ are shown in Figure 4. For $\mathrm{x}_{0}(0)=0$, the inltial layer correction $\mu_{0}(\tau)$ is trivial; however, the other two solutions have inftial layer jumps.

It can be easıly verıfied that $\alpha\left(x_{0}(t)\right)$ has a zero on $0<t<1$ when $(-3.08 \approx)-3 e / 2+1<x_{0}(0)<-1 / 2$. In this case $(4.5)$ has a turning point and $\mathrm{Y}_{10}$ becomes unbounded. Our theory and methods do not apply in this case; however, if $\varepsilon$ is not too small, the solution of (4.5) can be calculated using COLSYS. In order to contrast solutzons with and without turning points, we Illustrate $y_{1}(t, \varepsilon)$ for $\gamma=-2$ and $x_{0}(0)=-2.80$ in Figure 5.

Solutions obtained using SPCOL and the corresponding COLSYS corrections are shown for $\gamma=2$ and $x_{0}(0)=0,0.803$, and -4.29 in Tables 7, 9, and 11, respectively. The colsys correction falled to converge for $\varepsilon<10^{-6}$ when $x_{0}(0)=0$ and -4.29 . We have no explanation as to why the solution wzth $x_{0}(0)=0.803$ was so much easier to calculate. The relatıve difference between the SPCOL and COLSYS solutions for $x(1, \varepsilon)$ and $y_{2}(1, \varepsilon)$ are shown in Table 13 for $\gamma=2$ and $x_{0}(0)=-4.29$. These results are typical of those that we obtalned for all three solutions.

Using COLSYS with continuation in $\varepsilon$ and the default initial guess can find at most one solution, and, for this example, it found the $\mathrm{x}_{0}(0)=0$ solutzon. The results of this calculation are shown an Table 8 for $\gamma=2$. Although several $\varepsilon$ sequences were tried, we were unable to obtain convergence for $\varepsilon<10^{-6}$. Again, this situation could possibly be remedied by using collocation at the Gauss-Lobatto points as in Ascher and Werss $[2,3,4]$. The other two solutions when $\gamma=2$ can also be calculated using continuation in $\varepsilon$ provided that we use a sultable initial guess. Results for the solutions corresponding 


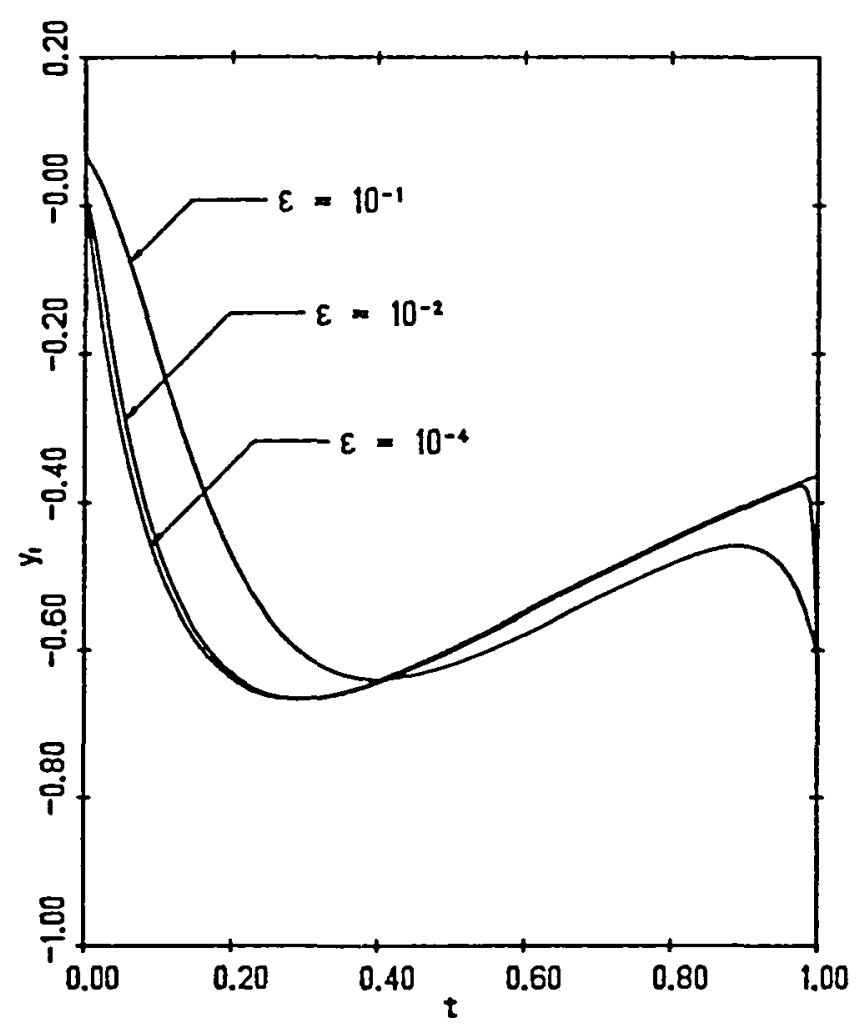

34.
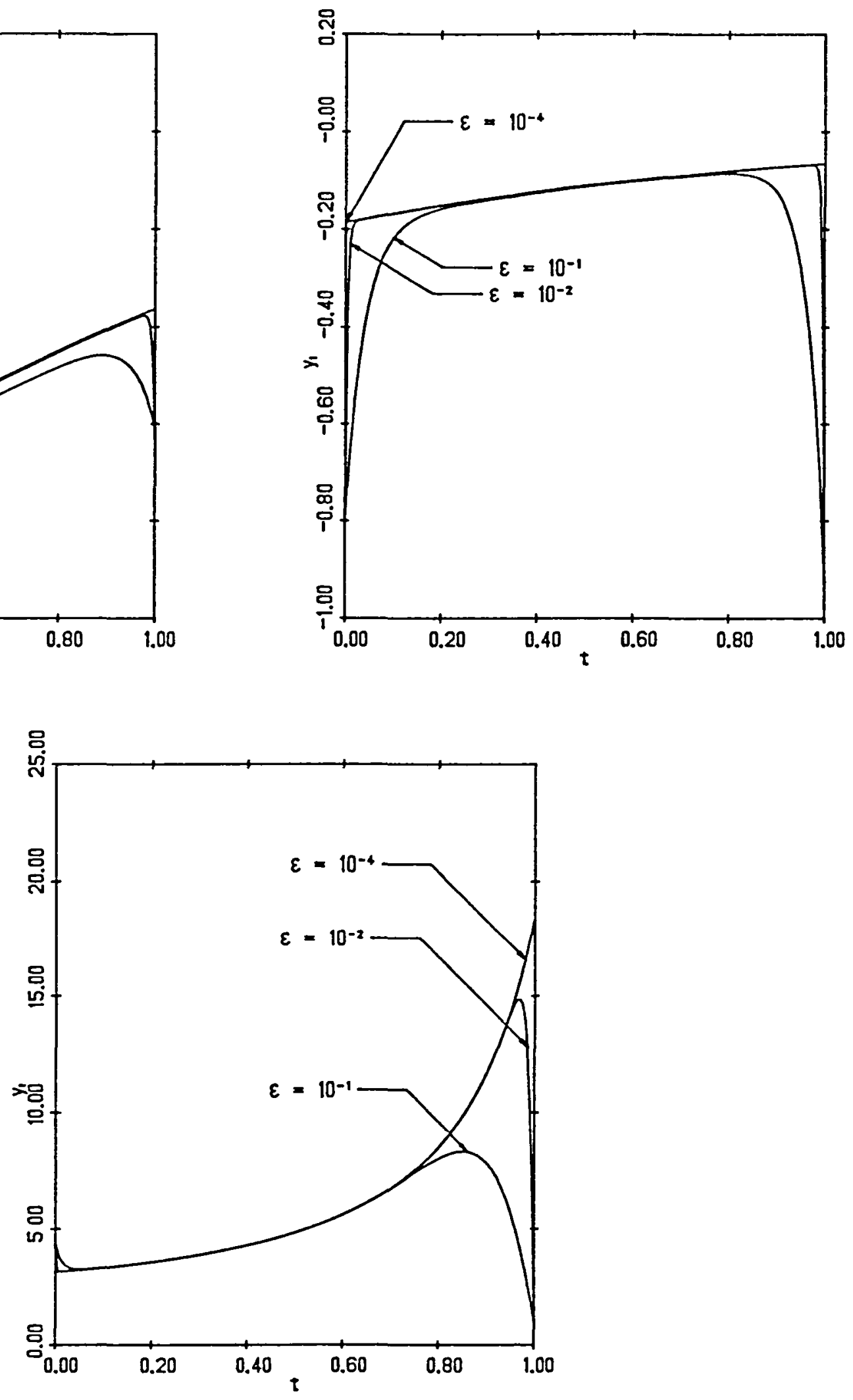

Figure 4. Numerical solution for $y_{1}(t)$ of Example 2 with $\gamma=2$ and $x_{0}(0)=0,0.803$, and -4.29 . 


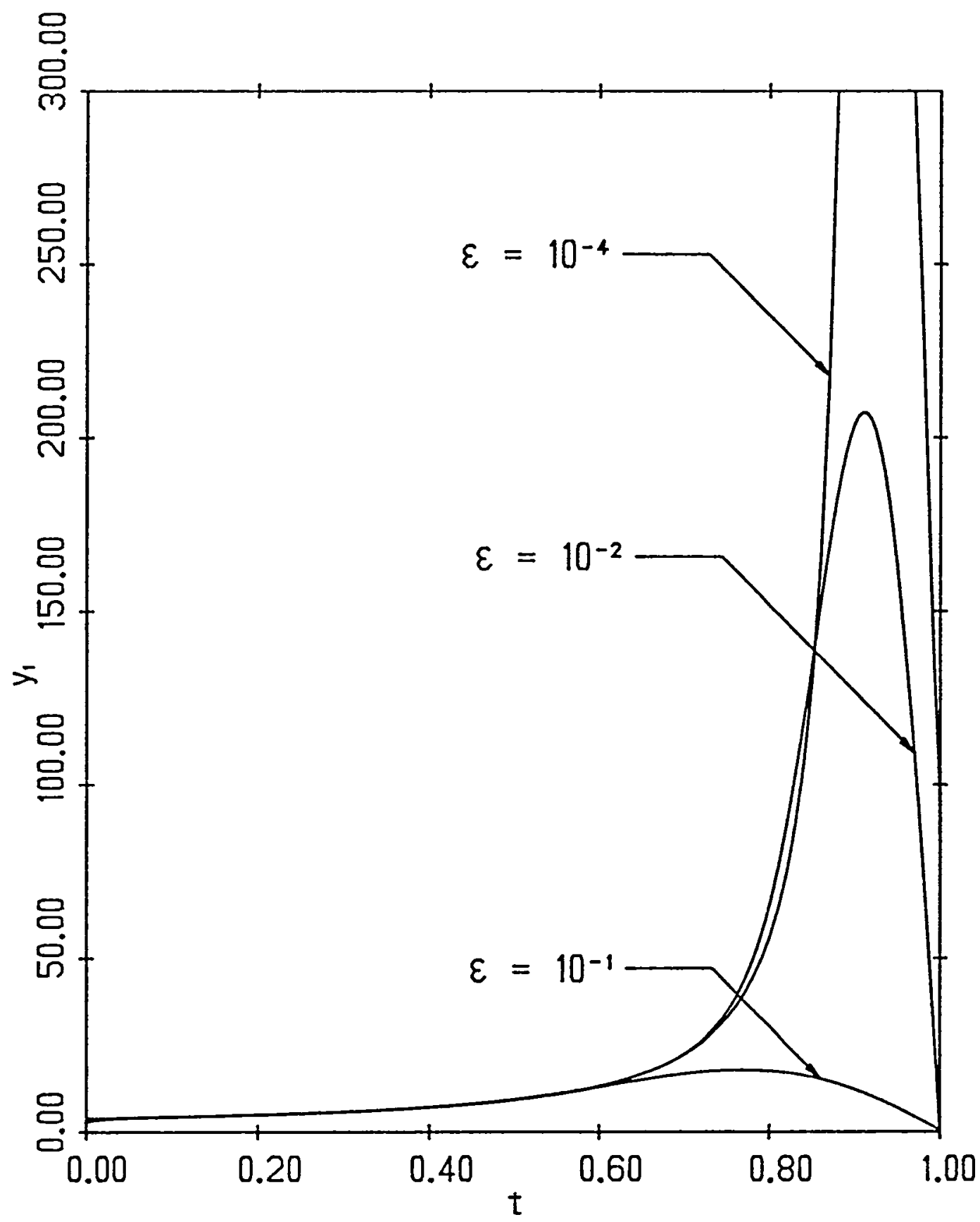

Figure 5. Numerical solution for $y_{1}(t)$ of Example 2 with $\gamma=2$ and $x_{0}(0)=-2.80$ 
to $\mathrm{x}_{0}(0)=0.803$ and -4.29 are presented in Tables 10 and 12 , respectively, using continuation with SPCOL furnishing an initial guess. These results seem to pornt to the possibrlity of using a combrnation of asymptotics and continuation to solve singular perturbation problems.

\section{Discussion.}

We have obtained asymptotic approximations for a restricted class of nonlinear singularly perturbed two-point boundary value problems and have shown how to construct approximate solutions numerically and use them to suggest a nonunzform mesh that may be used as input to a two-point boundary value code in order to calculate improved solutions. Clearly this approach offers some advantages over the more standard technique of continuation in $\varepsilon$ steps; however, the plcture is far from clear and several questions still remain as to how best to use asymptotic analysis in conjunction with numerical analysis.

In Example 2 of Section 4 we have shown that asymptotic methods may be used to distinguish different solutions in problems having multiple solutions. These asymptotzc approximations may be used to provide initial guesses to a two-polnt boundary value code.

In Example 1 of Section 4 we have shown that unbounded solutions can result from seemingly munor changes in the boundary conditions of singularly perturbed boundary value problems. Other very diverse behaviors can occur when turnıng point problems are consıdered (cf., e.g., Kevorkıan and cole [18] or O'Malley [20]). Since phenomena cannot easily be predicted, a sensible 


\begin{tabular}{|c|c|c|c|c|c|}
\hline \multirow{2}{*}{$\varepsilon$} & \multicolumn{2}{|c|}{ SPCOL } & \multicolumn{2}{|c|}{ COLSYS } & \multirow{2}{*}{ CORRECTION } \\
\cline { 2 - 6 } & NSUB & CP & NSUB & CP & TOTAL CP \\
\hline $10^{-1}$ & 40 & 0.6 & 88 & 6.3 & 6.9 \\
$10^{-2}$ & 44 & 0.6 & 88 & 6.2 & 6.8 \\
$10^{-4}$ & 47 & 0.6 & 192 & 18.2 & 18.8 \\
$10^{-6}$ & 47 & 0.6 & & & \\
\hline
\end{tabular}

TABLE 7. EXAMPLE 2 WITH $\gamma=2$ AND $x_{0}(0)=0$. NUMBER OF SUBINTERVALS (NSUB) AND CP TIMES TO SOLVE THE PROBLEM BY SPCOL AND TO IMPROVE IT BY COLSYS. THE CP TIMES INCLUDE THE TIME TO CALCULATE THE REDUCED SOLUTION, WHICH WAS 0.5 TIME UNITS. TOTAL CP IS THE SUM OF THE SPCOL CP AND THE COLSYS CP.

\begin{tabular}{|c|c|c|c|}
\hline$\varepsilon$ & NSUB & CP & TOTAL CP \\
\hline $10^{-1}$ & 40 & 1.8 & 1.8 \\
$10^{-2}$ & 44 & 3.3 & 5.2 \\
$10^{-4}$ & 264 & 13.4 & 18.6 \\
$10^{-5}$ & 372 & 20.2 & 38.7 \\
\hline
\end{tabular}

TABLE 8. EXAMPLE 2 WITH $\gamma=2$ and $x_{0}(0)=0$. NUMBER OF SUBINTERVALS (NSUB) AND CP TIMES TO SOLVE THE PROBLEM BY COLSYS WITH CONTINUATION IN $\varepsilon$ FROM $\varepsilon=10^{-1}$. THE DEFAULT INITIAL GUESS THAT IS PROVIDED IN COLSYS WAS USED TO START THE CONTINUATION SEQUENCE. TOTAL CP IS THE ACCUMULATED TIME FOR THE SEQUENCE. 


\begin{tabular}{|l|c|c|c|c|c|}
\hline \multirow{2}{*}{$\varepsilon$} & \multicolumn{2}{|c|}{ SPCOL } & \multicolumn{2}{c|}{ COLSYS } & \multirow{2}{*}{ CORRETION } \\
\cline { 2 - 6 } & NSUB & CP & NSUB & CP & TOTAL CP \\
\hline $10^{-1}$ & 42 & 1.5 & 42 & 3.0 & 4.5 \\
$10^{-2}$ & 52 & 1.6 & 52 & 3.0 & 4.6 \\
$10^{-4}$ & 57 & 1.6 & 58 & 2.6 & 4.2 \\
$10^{-6}$ & 57 & 1.6 & 114 & 10.9 & 12.5 \\
\hline
\end{tabular}

TABLE 9. EXAMPLE 2 WITH $\gamma=2$ AND $x_{0}=0.803$. NUMBER OF SUBINTERVALS (NSUB) AND CP TIMES TO SOLVE THE PROBLEM BY SPCOL AND TO IMPROVE IT BY COLSYS. THE CP TIMES INCLUDE THE TIME TO CALCULATE THE REDUCED SOLUTION, WHICH WAS 1.5 TIME UNITS. TOTAL CP IS THE SUM OF THE SPCOL CP AND THE COLSYS CP.

\begin{tabular}{|c|c|c|c|}
\hline$\varepsilon$ & NSUB & CP & TOTAL CP \\
\hline $10^{-4}$ & 58 & 2.6 & 2.6 \\
$10^{-5}$ & 58 & 2.4 & 5.0 \\
$10^{-6}$ & 70 & 4.3 & 9.3 \\
\hline
\end{tabular}

TABLE 10. EXAMPLE 2 WITH $\gamma=2$ AND $x_{0}(0)=0.803$. NUMBER OF SUBINTERVALS (NSUB) AND CP TIMES TO SOLVE THE PROBLEM BY COLSYS WITH CONTINUATION IN $\varepsilon$ FROM $\varepsilon=10^{-4}$. TOTAL CP IS THE ACCUMULATED TIME FOR THE SEQUENCE. 


\begin{tabular}{|c|c|c|c|c|c|}
\hline \multirow{2}{*}{$\varepsilon$} & \multicolumn{2}{|c|}{ SPCOL } & \multicolumn{2}{|c|}{ COLSYS } \\
\cline { 2 - 5 } & NSUB & CP & NSUB & CP & TOTAL CP \\
\hline $10^{-1}$ & 44 & 0.9 & 62 & 3.6 & 4.5 \\
$10^{-2}$ & 52 & 0.9 & 84 & 3.8 & 4.7 \\
$10^{-4}$ & 59 & 0.9 & 232 & 15.3 & 16.2 \\
$10^{-6}$ & 59 & 0.9 & & & \\
\hline
\end{tabular}

TABLE 11. EXAMPLE 2 WITH $\gamma=2$ AND $x_{0}(0)=-4.29$. NUMBER OF SUBINTERVALS (NSUB) AND CP TIMES TO SOLVE THE PROBLEM BY SPCOL AND TO IMPROVE IT BY COLSYS. THE CP TIMES INCLUDE THE TIME TO CALCULATE THE REDUCED SOLUTION, WHICH WAS 0.9 TIME UNITS. TOTAL CP IS THE SUM OF THE SPCOL CP AND THE COLSYS CP.

\begin{tabular}{|c|c|c|c|}
\hline$\varepsilon$ & NSUB & CP & TOTAL CP \\
\hline $10^{-2}$ & 84 & 3.8 & 3.8 \\
$10^{-4}$ & 168 & 21.3 & 25.1 \\
$10^{-6}$ & 322 & 40.8 & 65.9 \\
\hline
\end{tabular}

TABLE 12. EXAMPLE 2 WITH $\gamma=2$ AND $x_{0}(0)=-4.29$. NUMBER OF SUBINTERVALS (NSUB) AND CP TIMES TO SOLVE THE PROBLEM BY COLSYS WITH CONTINUATION IN $\varepsilon$ FROM $\varepsilon=10^{-2}$. TOTAL CP IS THE ACCUMULATED TIME FOR THE SEQUENCE. 
40 .

\begin{tabular}{|c|c|c|}
\hline$\varepsilon$ & $\frac{\Delta x(1, \varepsilon)}{\mid x(1, \varepsilon) \operatorname{COLSYS} T}$ & $\frac{\Delta y_{2}(1, \varepsilon)}{T_{2}(1, \varepsilon) \operatorname{coLSYS} T}$ \\
\hline $10^{-1}$ & $9.7 \times 10^{-3}$ & $2.4 \times 10^{-1}$ \\
$10^{-2}$ & $9.6 \times 10^{-4}$ & $3.9 \times 10^{-2}$ \\
$10^{-4}$ & $9.6 \times 10^{-6}$ & $4.3 \times 10^{-4}$ \\
$10^{-6}$ & $1.0 \times 10^{-7}$ & $4.5 \times 10^{-6}$ \\
\hline
\end{tabular}

TABLE 13. EXAMPLE 2 WITH $\gamma=2$ and $x_{0}(0)=-4.29$. RELATIVE DIFFERENCE BETWEEN SPCOL AND COLSYS SOLUTIONS WITH $\Delta():=\left|()_{\text {SPCOL }^{-}}()_{\text {COLSYs }}\right|$. 
course to follow is perhaps to use asymptotic and numerical methods in tandem. For example, a rough numerical solution could be obtained for several values of $\varepsilon$ which could then be used to suggest the form of an asymptotic solution. The asymptotic approximation could then be used to refine the numerıcal solution, and so on. It is also possible that singular perturbation theory could be used to construct special methods that are appropriate for speczfıc problems as e.g., in Flaherty and Mathon [9] and Ascher and Weiss [2, $3,4]$. 


\section{REFERENCES}

1. U. Ascher, I. Christzansen, and R. D. Russell, "Collocation software for boundary value ODE's", ACM Trans. Math. Software, Vol. 7 (1981), pp 209-222.

2. U. Ascher and R. Weiss, "Collocation for singular perturbation problems I: First order systems with constant coefficients", to appear SIAM J. Numer. Anal., 1983.

3. U. Ascher and R. Weiss, "Collocation for singular perturbation problems II: Linear first order systems without turning points", Tech. Rep. 82-4, Dept. Comp. Sci. University of Britısh Columbia, 1982.

4. U. Ascher and R. Weiss, "Collocation for singular perturbation problems III: Nonlinear problems wzthout turning points", Tech. Rep. 82-9, Dept. Comp. Sci. Unzversity of Brztish Columbia, 1982.

5. A. Bjorck, "A block $Q R$ algorıthm for partitioning stiff differential systems", Rep. LITH-MAT-82-44, Linkoping University, 1982

6. B. Chrlds, M. Scott, J. W. Danıel, E. Denman, and P. Nelson (Eds.), Codes for Boundary-Value Problems in ordinary Differential Equations, Proceedıngs of a Workang Conference, May 14-17, 1978, Lecture Notes in Computer Scıence, No. 76, Springer-Verlag, Berlın, 1979.

7. W. Enrıght, T. E. Hull, and B. Lindberg, "Comparing methods for stiff systems of O.D.E.'s", BIT, Vol. 54 (1976), pp 66-93.

8. W. E. Ferguson, Jr., A Singularly Perturbed Linear Two-Point Boundary Value Problem, Ph.D. dissertation, Calıfornıa Instıtute of Technology, Pasadena, 1975 .

9. J. E. Flaherty and W. Mathon, "Collocation with polynomial and tension splines for singularly-perturbed boundary value problems", SIAM J. Sc1. stat. Comput., Vol. 1 (1980), pp 260-289.

10. J. E. Flaherty and R. E. O'Malley, Jr., "On the numerlcal integration of two-point boundary value problems for stiff systems of ordinary differential equations", in J. J. H. Miller (Ed.), Boundary and Interıor Layers - Computational and Asymptotıc Methods, Boole Press, Dublin, 1980, pp 93-102.

11. J. E. Flaherty and R. E. O'Malley, Jr., "Singularly perturbed boundary value problems for nonlinear systems, including a Challenging problem for a nonlinear beam", in W. Eckhaus and E. H. deJager (Eds.), Theory and Applications of Singular Perturbations, Lecture Notes in Mathematics, No. 942, Springer-Verlag, Berlin, 1982, pp 170-191.

12. J. E. Flaherty and R. E. O'Malley, Jr., "Asymptotic and numerlcal methods for vector systems of boundary value problems", Proc. 1982 Army Numerical Analysis and Computers Conf., ARO Rep. 82-3, 1982, pp 381-395. 
13. G. H. Golub and J. H. Wilkinson, "Ill-condltioned elgensystems and the computation of the Jordan canonical form", SIAM Review, Vol. 18 (1976), pp 578-619.

14. W. A. Harrıs, Jr., "Singular perturbations of two-point boundary value problems for systems of ordinary differential equations", Arch. Rational Mech. Anal., Vol. 5 (1960), pp. 212-225.

15. P. W. Hemker, A Numerıcal study of Stıff Two-Point Boundary Value Problems, Mathematıcal Centre Tracts 80, Ams terdam, 1977.

16. F. C. Hoppensteadt, "Properties of solutions of ordinary differential equations with a small parameter", Comm. Pure Appl. Math., Vol. 24 (1971), pp 807-840.

17. F. A. Howes, "Some old and new results on singularly perturbed boundary value problems", Singular Perturbations and Asymptotics, R. E. Meyer and S. V. Parter, edıtors, Academıc Press, New York, 1980.

18. J. Kevorkian and J. D. Cole, Perturbation Methods in Applied Mathematics, Applied Mathematical Sciences 34, Springer-Verlag, New York, 1981 .

19. B. Kreıss and H. O. Kreiss, "Numerıcal methods for singular perturbation problems", SIAM J. Numer. Anal., Vol. 18 (1981), pp 262-276.

20. R. E. O'Malley, Jr., Introduction to Singular Perturbations, Academlc Press, New York, 1974.

21. R. E. O'Malley, Jr., "On multiple solutions of singularly perturbed systems in the conditionally stable case", in R. E. Meyer and S.V. Parter (Eds.), Singular Perturbations and Asymptotics, Academic Press, New York, 1980, pp. 87-108.

22. R. E. O'Malley, Jr., "Shock and transition layers for singularly perturbed second order vector systems", to appear SIAM J. Appl. Math.

23. S. Osher, "Numerical singular perturbation problems and one-sided difference schemes", SIAM J. Numer. Anal., Vol. 18 (1981), pp 129-144.

24. C. E. Pearson, "On a differential equation of the boundary layer type", J. Math. and Phys., Vol. 47 (1968), pp 134-154.

25. C. E. Pearson, "On non-linear ordinary differential equations of boundary layer type", J. Math. and Phys., Vol. 47 (1968), pp 351-358.

26. A. Ruhe, "An algorıthm for numerıcal determinatzon of the structure of a general matrix", BIT, Vol. 10 (1970), pp 196-216.

27. R. D. Russell and I. Christiansen, "Adaptive mesh strategies for solving boundary value problems", SIAM J. Numer. Anal., Vol. 15 (1978), pp 59-80.

29. W. Wasow, "On the asymptotıc solution of boundary value problems for ordinary differential equations containing a parameter", J. Math. and Phys., Vol. 23 (1944), Pp 173-183. 


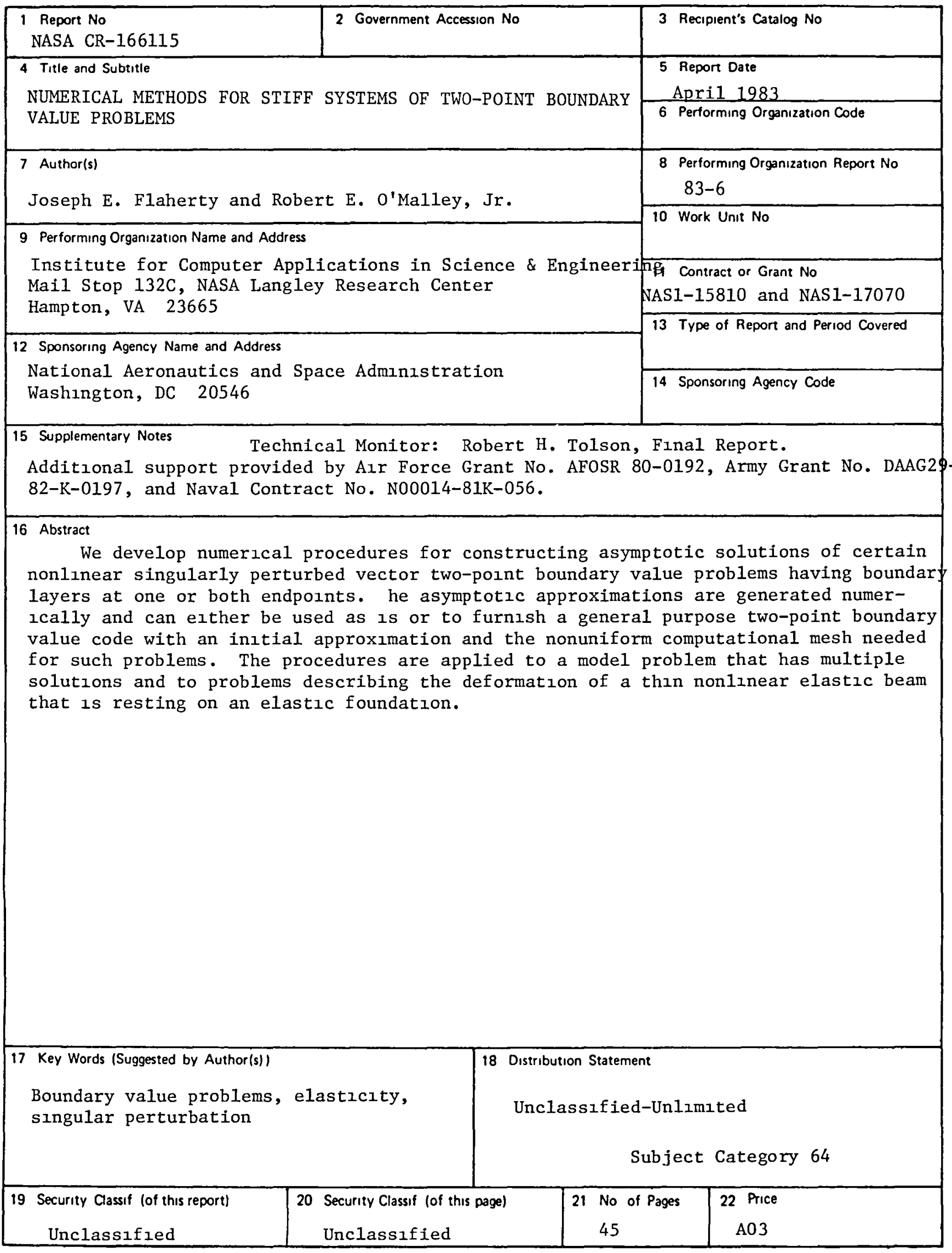




\section{End of Document}

